\title{
Sodium-Based Batteries: In Search of the Best Compromise Between Sustainability and Maximization of Electric Performance
}

\begin{abstract}
Duygu Karabelli ${ }^{1 *}$, Soumya Singh ${ }^{1}$, Steffen Kiemel ${ }^{1}$, Jan Koller ${ }^{2}$, Aishuak Konarov ${ }^{3}$, Frank Stubhan ${ }^{4}$, Robert Miehe ${ }^{1}$, Max Weeber ${ }^{1}$, Zhumabay Bakenov ${ }^{3}$ and Kai Peter Birke ${ }^{1,5}$

${ }^{1}$ Fraunhofer Institute for Manufacturing Engineering and Automation IPA, Stuttgart, Germany, ${ }^{2}$ Fraunhofer Institute for Manufacturing Engineering and Automation IPA, Bayreuth, Germany, ${ }^{3}$ Department Chemical and Materials Engineering, School of Engineering and Digital Sciences, Nazarbayev University, Nur-Sultan, Kazakhstan; National Laboratory Astana, Nazarbayev University, Nur-Sultan, Kazakhstan, ${ }^{4} \mathrm{ACl}$-Systems GmbH, Zimmern ob Rottweil, Germany, ${ }^{5}$ Chair for Electrical Energy Storage Systems, Institute for Photovoltaics, University of Stuttgart, Stuttgart, Germany
\end{abstract}

Till 2020 the predominant key success factors of battery development have been overwhelmingly energy density, power density, lifetime, safety, and costs per kWh. That is why there is a high expectation on energy storage systems such as lithium-air $\left(\mathrm{Li}-\mathrm{O}_{2}\right)$ and lithiumsulfur (Li-S) systems, especially for mobile applications. These systems have high theoretical specific energy densities compared to conventional Li-ion systems. If the challenges such as practical implementation, low energy efficiency, and cycle life are handled, these systems could provide an interesting energy source for EVs. However, various raw materials are increasingly under critical discussion. Though only $3 \mathrm{wt} \%$ of metallic lithium is present in a modern Li-ion cell, absolute high amounts of lithium demand will rise due to the fast-growing market for traction and stationary batteries. Moreover, many lithium sources are not available without compromising environmental aspects. Therefore, there is a growing focus on alternative technologies such as $\mathrm{Na}$-ion and $\mathrm{Zn}$-ion batteries. On a view of $\mathrm{Na}$-ion batteries, especially the combination with carbons derived from food waste as negative electrodes may generate a promising overall cost structure, though energy densities are not as favorable as for Li-ion batteries. Within the scope of this work, the future potential of sodium-based batteries will be discussed in view of sustainability and abundance vs. maximization of electric performance. The major directions of cathode materials development are reviewed and the tendency towards designing high-performance systems is discussed. This paper provides an outlook on the potential of sodium-based batteries in the future battery market of mobile and stationary applications.

Keywords: sodium battery chemistries, $\mathrm{X}$ electric vehicle, stationary batteries, $\mathrm{Na-ion}$ batteries, post-Li-ion technologies, raw materials, battery cost

\section{INTRODUCTION}

Among secondary batteries, lithium-ion batteries (LIBs) play an important role in many areas of energy storage systems. Since their first commercialization by Sony in 1991, further research efforts have been devoted to the LIBs technology. However, the highest achievable energy density for LIBs in the near future (around 250-260 $\mathrm{Wh} \mathrm{kg}^{-1}$ ) is insufficient (Ding et al., 2019), thus limiting the range 
of practical electric vehicles (EVs). As a fact, there is a high demand and interest for other energy storage technologies with higher energy densities. Lithium-air $\left(\mathrm{Li}-\mathrm{O}_{2}\right)$ and lithium-sulfur (Li-S) systems have higher theoretical specific energy densities (3,600 and 2,600 $\mathrm{Wh} \mathrm{kg}^{-1,}$ respectively) compared with those for LIBs (Liu et al., 2018). Nevertheless, the cycle lifetime and safety concerns have to be overcome in order to have a mature technology. Moreover, one of the major concerns is that the markets will be facing depletion of lithium sources and, as a result, high production cost if recycling technology is not implemented on a large scale (Al-Thyabat et al., 2013; Ahmadi et al., 2017; Dolega, 2019; Ambrose and Kendall, 2020a; Ambrose and Kendall, 2020b).

Taking into account that it is already difficult to scale current LIBs for a different type of applications (e.g., grid-scale storage) mainly due to production and maintenance costs (Etacheri et al., 2011; Habib and Sou, 2018; Chen et al., 2020; Cole and Frazier, 2019), the cutting-edge innovations in battery energy storage systems (BESS) is indispensable in order to achieve highperformance, cost-efficient and environmentally friendly batteries. Novel beyond lithium-ion chemistries (e.g., sodium, potassium, magnesium and zinc) have been developed in order to address the present limitations of conventional LIBs (Ellis and Nazar, 2012; Yabuuchi et al., 2014; Barker, 2017; Hwang et al., 2017; Delmas, 2018; You and Manthiram, 2018; Li et al., 2019; MacLaughlin, 2019; Ming et al., 2019). Among many anode candidates, Sodium (Na) based anodes have attracted tremendous attention, thanks to mainly high $\mathrm{Na}$ abundance (the fourth abundant metallic element), low supply cost $\left(\mathrm{Na}_{2} \mathrm{CO}_{3}, \$ 150\right.$ ton $^{-1} ; \mathrm{Li}_{2} \mathrm{CO}_{3}, \$ 5,000$ ton $\left.^{-1}\right)$, as well as its safety (Zhao et al., 2017). However, LIBs technology is a mature technology, and there are currently no equivalent alternatives to LIBs. Since lithium is very light and has a high theoretical specific capacity $\left(3,860 \mathrm{mAh} \mathrm{g}^{-1}\right)$ (Liu et al., 2018), it is very challenging to compensate for it, for high capacity and lowcost battery production. Indeed, the studies show that the overall cost of Na-ion Batteries (SIBs) is still higher than that of LIBs (in terms of $\left.\$ \mathrm{kWh}^{-1}\right)$, even though $\mathrm{Na}$ itself is a cheaper anode material.

The crucial question is: What is the cost-effectiveness of $\mathrm{Li}$ recycling in the future? The prospect of producing large modules will increase the cost of LIBs with uncertainties in the supply of lithium. At present, one-third of the lithium produced worldwide is already being used by the LIBs industry. Last but not least, the availability of other LIBs main raw materials, particularly cobalt, are facing market instabilities due to political and environmental requirements. If it is possible to close the loop for LIBs and to establish a circular economy, in this case, the manufacturers will not be looking for alternatives. In case of sodium, there will be no pressure for "low-cost recycling" since $\mathrm{Na}$ can easily be obtained by evaporation of seawater $\left(11,000 \mathrm{mg} \mathrm{L}^{-1}\right.$ in seawater) where the lithium content in seawater is much lower than that of $\mathrm{Na}$ $\left(0.18 \mathrm{mg} \mathrm{L}^{-1}\right.$ ) (Adelhelm et al., 2015). From this perspective, sodium-based batteries are well suited to mass production and the manufacture of large modules.

High-temperature Sodium/sulfur has already been commercialized for decades with liquid sodium at $300^{\circ} \mathrm{C}$
(Oshima et al., 2004). Its specific capacity is indeed lower than the one of actual LIBs since this battery system needs a solid housing and thermal insulation. Moreover, the presence of liquid $\mathrm{Na}$ obstructs its application in EVs. That type of batteries can be considered most likely for low-cost stationary energy storage systems.

The concept of rechargeable sodium-air $\left(\mathrm{Na}-\mathrm{O}_{2}\right)$ systems has also been reported (Zhao et al., 2014; Landa-Medrano et al., 2016). The $\mathrm{Na}-\mathrm{O}_{2}$ cell indeed shows some promising advantages over the $\mathrm{Li} / \mathrm{O}_{2}$ because the discharge reaction product $\mathrm{NaO}_{2}$ presents higher energy efficiency and reversibility (Zhao et al., 2014). Nevertheless, it is still in the initial stage of development and faces significant challenges such as higher cycle numbers, minimization of side reaction products. As it is like in $\mathrm{Na}-\mathrm{S}$, this type of battery is also very unlikely to be used in EVs.

Apart from $\mathrm{Na}-\mathrm{S}$ and $\mathrm{Na}-\mathrm{O}_{2}$ technologies, SIBs can be considered as more realistic alternative energy storage technology to today's LIBs (Ellis and Nazar, 2012; Ponrouch et al., 2015; Hwang et al., 2017; Bin et al., 2018). The most common cathodes for SIBs are sodium oxides $\left(\mathrm{NaMO}_{2}, \mathrm{M}=\mathrm{V}\right.$, $\mathrm{Fe}, \mathrm{Mn}, \mathrm{Cu}$, Co., and $\mathrm{Ni})$, sodium phosphates $\left(\mathrm{Na}_{7} \mathrm{~V}_{3}\left(\mathrm{P}_{2} \mathrm{O}_{7}\right)_{4}\right.$, $\mathrm{NaFePO}_{4}$, transition metal oxides $\left(\mathrm{V}_{2} \mathrm{O}_{5}\right)$ and Prussian blue $(\mathrm{PB}$, $\mathrm{Na}_{2} \mathrm{M}\left[\mathrm{Fe}(\mathrm{CN})_{6}\right]$ ) (Ellis and Nazar, 2012; Delmas, 2018). A British company Faradion has recently announced that its high energy $\mathrm{Na}-\mathrm{MO}_{2}$ cells will be used in commercial EVs in India and declared that they estimate $30 \%$ of cost reduction at the cell level (Barker, 2017). Previously, the company had conducted several prototype demonstrations, including e-bikes and golf trolleys, but the project in Australia poses a more significant engineering challenge for today's SIBs technology. Apart from Faradion, a start-up company Tiamat (France) and HiNa Battery Technology (China), and other key innovators, have built SIB prototypes for low-speed EVs, start\&stop $12 \mathrm{~V}$ batteries, e-bikes, and e-scooters.

Two different types of electrolytes can be introduced for SIBs: i) aqueous and ii) organic (Ellis and Nazar, 2012; Delmas, 2018). The aqueous medium can be favorable due to:

- Low risk of explosion or flammability of the battery during heating;

- No strict control of humidity during assembly, which reduces the cost of the battery;

- High ionic conductivity

However, a narrow potential window remains a major obstacle, and very few materials can operate in an aqueous environment (Vignarooban et al., 2016; Bin et al., 2018).

At present, most sodium-ion batteries contain an organic electrolyte. These electrolytes generally consist of a sodium salt dissolved in one or more organic solvents. The most commonly used organic solvents are carbonates such as pro; pylene carbonate (PC), ethylene carbonate (EC), dimethyl carbonate (DMC), fluoro-ethylene carbonate (FEC) or vinylene carbonate (VC) (Ponrouch et al., 2015; Vignarooban et al., 2016; Zhao et al., 2017).

This paper discusses beyond Li-ion chemistry with a focus on organic electrolyte-based SIBs. This technology is being analyzed 
in terms of performance and cost and is then compared to today's LIBs technology in order to make a prediction in which use case scenarios, the SIBs potentially will outperform existing LIBs.

The methodology is based on literature research, followed by analysis of material/cost and effect of $\mathrm{Na}$ batteries on circular economy. This study is presented by authors with an interdisciplinary background (Material science, electrochemistry, raw material refinement, and recycling).

\section{SODIUM-ION BATTERIES WITH ORGANIC ELECTROLYTE}

\section{State-of-the-Art}

Development of renewable and environmentally responsible organic electrolyte based SIBs has gained remarkably increased attention in the past 6 years (Adelhelm et al., 2015; Barker, 2017; Bauer et al., 2018). To arrive at implications regarding the performance and cost of SIBs and to address the critical questions from the introduction, the first step of this study reviews the existing literature about organic electrolyte-based SIBs. These type of electrolytes are prepared by dissolving one of ionic sodium salts $\left(\mathrm{NaClO}_{4}, \mathrm{NaPF}_{6}\right.$ and NaTFSI) in a nonaqueous solvents such as EC, PC, DMC, DEC, DME, like in Li-ion batteries (Vignarooban et al., 2016). It has been reported that an ionic conductivity of an electrolyte prepared with $1 \mathrm{M} \mathrm{NaClO}_{4}$ in EC:DME (50:50 wt\%) reached to $12.5 \mathrm{~ms} \mathrm{~cm}^{-1}$ which is almost the same value as the electrolyte prepared with $1 \mathrm{M} \mathrm{LiPF}_{6}$ in EC: DMC (50:50 wt\%) (Vignarooban et al., 2016).

The large atomic radius of $\mathrm{Na}\left(0.97 \AA\right.$ for $\mathrm{Na}^{+}$and $0.68 \AA$ for $\mathrm{Li}^{+}$), causes sluggish sodium diffusion kinetics and large volume expansion, which are both critical parameters for revolutionary power density performance that can meet the real needs of power grids and large-scale EESs (Chen et al., 2019). Therefore, it is important to explore novel cathode materials for SIBs with improved $\mathrm{Na}$ kinetics (Chen et al., 2020). The energy density of the Na-ion batteries is directly related to the cathode material's performance. Similar to LIBs, sodium cathodes are divided into three main groups: layered, olivine (NASICON), and spinel. Among them, layered oxides (Guo et al., 2014; Liu et al., 2015; Ortiz-Vitoriano et al., 2017; Konarov et al., 2018; Deng et al., 2018; Li et al., 2019) and NASICON structure phosphates showed promising performance (Chen et al., 2019). More recently, Prussian blue analogs [PBAs, $\mathrm{Na} 2 \mathrm{M}[\mathrm{Fe}(\mathrm{CN}) 6], \mathrm{M}=\mathrm{Fe}, \mathrm{Co}$, $\mathrm{Mn}, \mathrm{Ni}, \mathrm{Cu}$, etc.] have been extensively studied due to their large gaps in lattice space structure, which can provide abundant sites and transport channels for reversible de-intercalation of sodium-ion (Luo et al., 2017; Wang et al., 2018; You et al., 2014).

Layered oxide compounds that are of interest as cathode materials for SIBs have a common formula $\mathrm{Na}_{\mathrm{x}} \mathrm{MO}_{2}$, where $\mathrm{M}$ denotes one or several transition metals ( $\mathrm{Ti}, \mathrm{V}, \mathrm{Cr}, \mathrm{Mn}, \mathrm{Fe}, \mathrm{Co}$, or Ni). 2D layered structure sodium transition metal oxides are widely studied due to their enhanced electrochemical performance compared with other compounds. These materials are classified as an $\mathrm{O} 3$ and $\mathrm{P} 2$ type structure which letter $\mathrm{O}$ and $\mathrm{P}$ represents the location of sodium ion in the crystal structure (P-prismatic site, O-octahedral site) (Figure 1). The numbers represent the transition metal layer in the repeating unit cell in the structure (Delmas, 2018). O3 and P2-types are the most-common structural polymorphs of layered oxides.The P2type structure has better ionic conductivity and delivers higher discharge capacity than the O3-type structure (Qi et al., 2017). Moreover, P2-type material is less hygroscopic than O3-type.

Among P2-type materials, manganese-based $\left(\mathrm{Na}_{2 / 3} \mathrm{MnO}_{2}\right)$ cathode has been attracted much attention due to the low price of manganese, and it delivers high discharge capacity $\left(>150 \mathrm{mAh} \mathrm{g}^{-1}\right)$ compared to other studied cathodes (Zhu et al., 2018). However, the use of manganese causes structural distortions as the $\mathrm{Mn}^{3+}$ ions are dominant in the structure. This is associated with Jahn-Teller distortion, which consists of $\mathrm{Mn}^{3+}$ elongation or compression in the $z$-axis. The anisotropic changes in the lattice parameters during cycling lead to rapid capacity fading (Liu et al., 2015). One of the ways to overcome this problem is to dilute the concentration of $\mathrm{Mn}^{3+}$ ions in the crystal structure and decrease the anisotropic change by substituting it with other electrochemically active or nonactive metal cations (Guo et al., 2017; El Moctar et al., 2018; Kim et al., 2018; Irisarri et al., 2018).

In this matter, Clément et al. (2016) studied the effect of $\mathrm{Mg}$ doping on the P2-type $\mathrm{Na}_{2 / 3} \mathrm{MnO}_{2}$ compound by varying the amount of dopant: $\mathrm{Na}_{2 / 3} \mathrm{Mn}_{1-\mathrm{y}} \mathrm{Mg}_{\mathrm{y}} \mathrm{O}_{2}(y=0.0,0.05,0.1)$. Partial substitution of $\mathrm{Mn}^{3+}$ by $\mathrm{Mg}$ led to a smoother potential profile and enhanced the electrochemical performance of the composite. Successful doping by $\mathrm{Mg}$ suppressed the Jahn-Teller distortion, which reduced the number of $\mathrm{Mn}^{3+}$ by $\mathrm{Mg}$ in $\mathrm{P} 2-\mathrm{Na}_{2 / 3} \mathrm{MnO}_{2}$. Among the compositions, the 5\% Mg-doped compound delivered the highest capacity and better electrochemical properties compared to the one with $10 \% \mathrm{Mg}$ doping.

Kang et al. (2015) studied copper-substituted P2-type $\mathrm{Na}_{0.67} \mathrm{Cu}_{\mathrm{x}} \mathrm{Mn}_{1-\mathrm{x}} \mathrm{O}_{2}(x=0,0.14,0.25,0.33)$ compound to improve the electrochemical performance of P2-type $\mathrm{Na}_{0.7} \mathrm{MnO}_{2}$. When the amount of $\mathrm{Cu}$ increased in the composite, the discharge capacity decreased. However, the reaction potential increased due to the redox reaction of $\mathrm{Cu}^{2+}$ / $\mathrm{Cu}^{3+}$. In the case of $x=0.25$, both $\mathrm{Mn}$ and $\mathrm{Cu}$ were responsible for delivering the capacity. By substitution of part of $\mathrm{Mn}^{3+}$ by $\mathrm{Cu}$ led to significant improvement in the rate performance and stability of the material.

Lu and Dahn (2001) reported nickel substituted P2-type $\mathrm{Na}_{2 / 3}$ $\left[\mathrm{Mn}_{2 / 3} \mathrm{Ni}_{1 / 3}\right] \mathrm{O}_{2}$ composite, where all the $\mathrm{Mn}^{3+}$ was replaced with $\mathrm{Ni}^{2+}$ due to the similarity of ionic sizes. Composite showed a high operating potential with $\mathrm{Ni}^{2+} / \mathrm{Ni}^{4+}$ redox pair and delivered a relatively high discharge capacity. Besides, the compound illustrated high operating potential $(\sim 3.5 \mathrm{~V})$ and stability in aqueous solution. Even after 1 year in water, the structure did not change much. The excellent properties of the P2-type $\mathrm{Na}_{2 / 3}$ $\left[\mathrm{Mn}_{2 / 3} \mathrm{Ni}_{1 / 3}\right] \mathrm{O}_{2}$ compound make it attractive for further commercialization. However, the compound suffered from rapid capacity fading; this fading does not relate to the JahnTeller distortion due to the absence of $\mathrm{Mn}^{3+}$. The phase change during cycling from the $\mathrm{P} 2$ to $\mathrm{O} 2$ was responsible for the capacity fade because of the large volume change ( 23\%) during phase transition. There have been many approaches to suppress this issue by partially substituting the Ni with other metals [Mg Zheng 


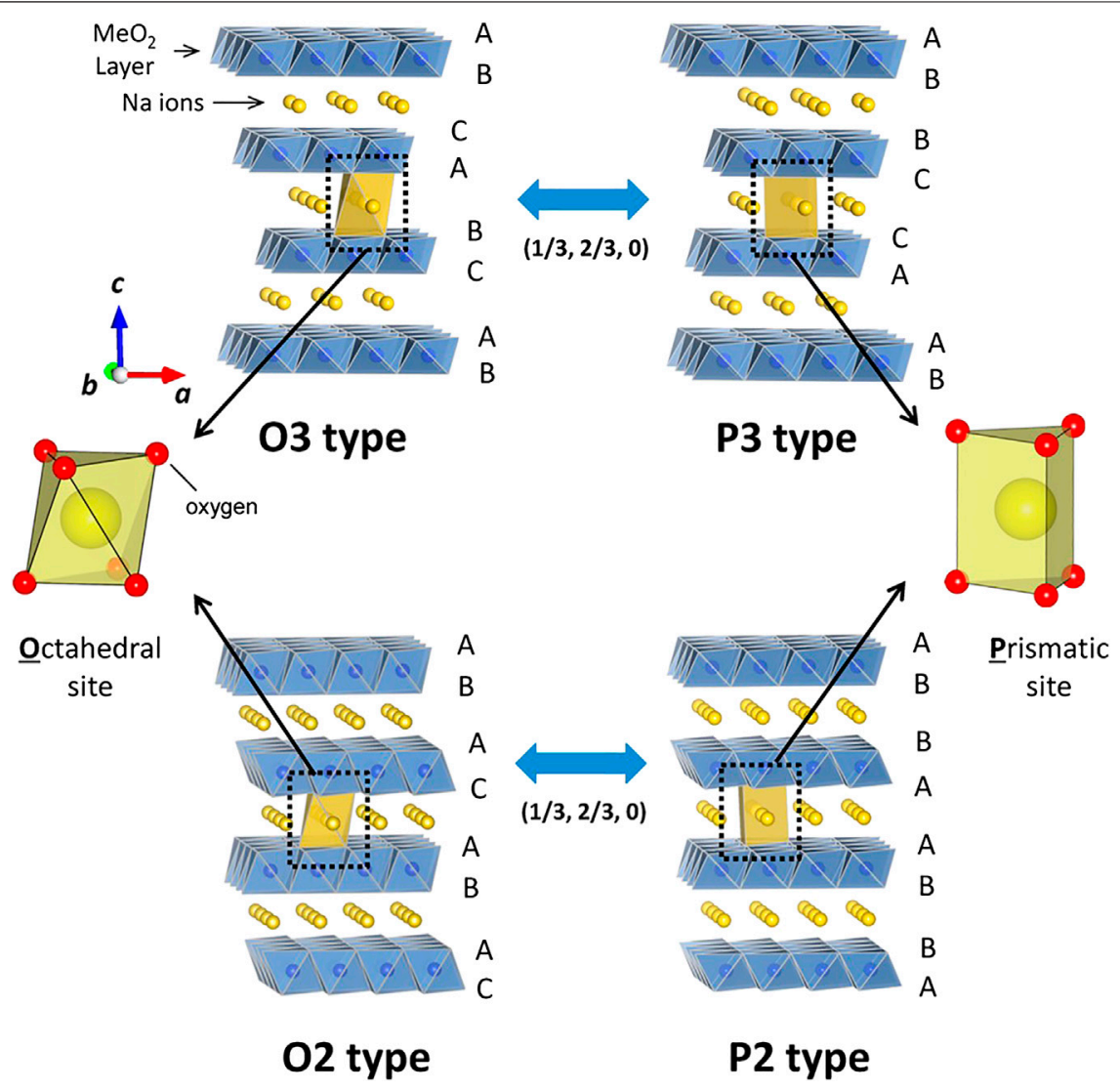

FIGURE 1 | Classification of $\mathrm{Na}-\mathrm{Me}-\mathrm{O}$ layered materials with sheets of edge-sharing MeO6 octahedra and phase transition processes induced by sodium extraction. Reprinted with permission from [ref. Yabuuchi et al. (2014)]. Copyright (2014) American Chemical Society.

et al. (2017), Cu Zheng et al. (2017), Zn Xu et al. (2014), Al Hasa et al. (2017), and Li Xu et al. (2014)].

Konarov et al. studied Konarov et al. (2018) the variation of $\mathrm{Ni}$ content in P2-type $\mathrm{Na}_{2 / 3} \mathrm{Mn}_{1-\mathrm{x}} \mathrm{Ni}_{\mathrm{x}} \mathrm{O}_{2}(x=0,0.1,0.2)$ in order to find the optimal performance, which is to suppress the Jahn-Teller distortion and phase change from P2 to O2. Among studied compounds, $\mathrm{Na}_{2 / 3}\left[\mathrm{Mn}_{0.8} \mathrm{Ni}_{0.2}\right] \mathrm{O}_{2}$ exhibited the optimal electrochemical properties. The compound delivered high capacity at high current densities $\left(10 \mathrm{C}=90 \mathrm{mAh} \mathrm{g}^{-1}\right)$ compared with the previously reported. Although a P2-O2 biphasic reaction occurred during the cycling, the volume change was only approximately $10 \%$, which is smaller than that for P2type $\mathrm{Na}_{2 / 3}\left[\mathrm{Mn}_{2 / 3} \mathrm{Ni}_{1 / 3}\right] \mathrm{O}_{2}$.

Ortiz-Vitoriano et al. (2017) provided a proof-of-concept for full cells utilizing layered sodium manganese oxides (Liu et al., 2015). The material $\mathrm{Na}_{0.78} \mathrm{Li}_{0.18} \mathrm{Ni}_{0.25} \mathrm{Mn}_{0.583} \mathrm{O}_{w}$ demonstrated moderate to good electrochemical performances, a high discharge capacity of $240 \mathrm{mAh} \mathrm{g}^{-1}$ in the voltage range of $1.5-4.5 \mathrm{~V}$, thus the total energy density of the material level reaches $675 \mathrm{Wh} \mathrm{kg}^{-1}$. When cycled between 1.5 and $4.2 \mathrm{~V}$, the discharge capacity was maintained at around $190 \mathrm{mAh} \mathrm{g}^{-1}$ after 30 cycles.

Yabuuchi et al. (2014) increased the concentration of electrochemically inactive $\mathrm{Mg}$ in $\mathrm{P} 2-\mathrm{Na}_{2 / 3} \mathrm{MnO}_{2}$ to $28 \%$, substituting almost all the $\mathrm{Mn}^{3+}$ ions and obtaining $\mathrm{Na}_{2 / 3}$ $\left[\mathrm{Mn}_{0.72} \mathrm{Mg}_{0.28}\right] \mathrm{O}_{2}$ compound where the manganese oxidation state was close to $4+$. Interestingly, electrochemically inactive material delivered about $150 \mathrm{mAh} \mathrm{g}^{-1}$ of capacity in the initial charge and over $200 \mathrm{mAh} \mathrm{g}^{-1}$ of capacity in the following cycles. An anomalously large reversible capacity is expected to originate from the oxygen redox and activation of $\mathrm{Mn}^{3+}$ in the following cycles, like in Li-rich cathodes. Lately, Bruce's group studied the same material $\left(\mathrm{Na}_{2 / 3}\left[\mathrm{Mn}_{0.72} \mathrm{Mg}_{0.28}\right] \mathrm{O}_{2}\right)$ and confirmed the reversible oxygen redox over cycles via state-of-art tools (Maitra et al., 2018). Unlike in Li-rich material, the activation of oxygen redox does not require alkali ions to be in the transition metal layer. Because of that, the oxygen loss was suppressed by $\mathrm{Mg}^{2+}$, which bond with oxygen, as in the case of Li-rich materials, when the Li-ion is removed from the transition metal layer, and it causes the non-bonded oxygen, which leads to oxygen evolution (Maitra et al., 2018).

Recently, Konarov et al. (2019) studied the effect of Mn substitution via $\mathrm{Zn}$ in $\mathrm{P} 2-\mathrm{Na}_{2 / 3} \mathrm{Mn}_{1-x} \mathrm{Zn}_{\mathrm{x}} \mathrm{O}_{2}(x=0,0.1,0.2$, 0.3 ). As the $\mathrm{Zn}$ content is increased, the capacity generated from the oxygen redox is increased. Among the different compositions, the $\mathrm{P} 2-\mathrm{Na}_{2 / 3} \mathrm{Mn}_{0.7} \mathrm{Zn}_{0.3} \mathrm{O}_{2}$ compound illustrated excellent electrochemical performance. The existence of $\mathrm{Zn}$ ion in the transition metal layer stabilized the crystal structure and 

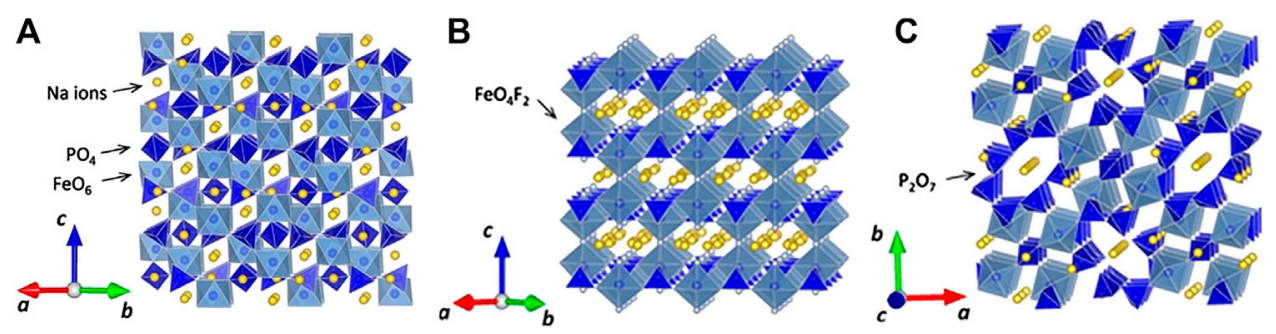

FIGURE 2 | Crystal structures for vanadium-based polyanionic compounds: (A) Na3V2(PO4)3 (NASICON-type), (B) Na3V2(PO4)2F3, and (C) Na7V4(P2O7)4PO4. Reprinted with permission from [ref. Yabuuchi et al. (2014)]. Copyright (2014) American Chemical Society.
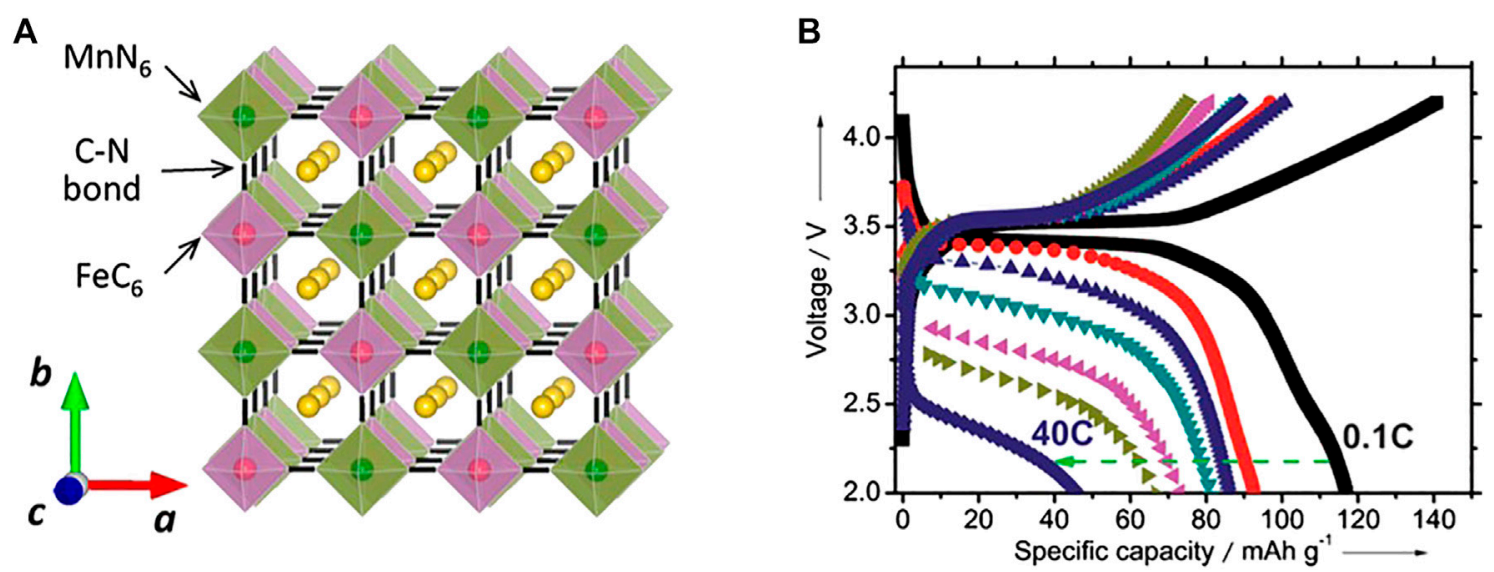

FIGURE 3 | (A) Crystal structure of $\mathrm{NaxMnFe}(\mathrm{CN}) 6$, and (B) Electrode performance of $\mathrm{NaxMnFe}(\mathrm{CN}) 6$ in Na cells. Reprinted with permission from ref. Yabuuchi et al. (2014)]. Copyright (2014) American Chemical Society.

triggered the oxygen redox. As a result, a discharge capacity of $190 \mathrm{mAh} \mathrm{g}^{-1}$ was delivered, and $80 \%$ of it remained after 200 cycles. However, the operating potential of such a system is comparatively low. To address this issue, the $\mathrm{Ni}$ was introduced to the crystal structure by substituting half of the $\mathrm{Zn}$ in structure ( $\left.\mathrm{P} 2-\mathrm{Na}_{2 / 3} \mathrm{Mn}_{0.7} \mathrm{Zn}_{0.15} \mathrm{Ni}_{0.15} \mathrm{O}_{2}\right)$. The addition of the $\mathrm{Ni}$ resulted in an increase in the operating potential to $3.5 \mathrm{~V}$ (Konarov et al., 2020).

Among NASICON type of cathodes which shown in Figure 2, $\mathrm{Na}_{3} \mathrm{~V}_{2}\left(\mathrm{PO}_{4}\right)_{3}$ and its derivatives exhibited excellent electrochemical performance (Guo et al., 2017). Even though the delivered capacity is smaller than the layered oxides, the operating potential makes it most promising. However, the price and toxicity of the vanadium limit its further steps to the market. Prussian blue (PB) and its analogs (PBAs) are a large family of transition-metal hexacyanoferrates with open framework structure, abundant redox-active sites, and strong structural stability. Particularly, due to their large ionic channels and interstices in the lattice, PBs are one of the few host materials that can accommodate larger alkali cations, such as $\mathrm{Na}^{+}$and $\mathrm{K}^{+}$ ions, for facile and reversible insertion reactions (Figure 3). Benefiting from this structural feature, $\mathrm{PB}$ compounds have been intensively investigated as a new alternative and low-cost $\mathrm{Na}$-insertion cathode during the past 5 years, although there is still room for improvement (Zhang, 2019). The intrinsic performance of PBAs electrodes is strongly affected by the presence of crystal imperfections, such as vacancies and water molecules. An increase in vacancies raises the coordinated water content, which reduces redox-active sites. Hence, these challenges, such as low discharge capacity, poor cyclic stability, and low Coulombic efficiency, need to be addressed before the commercialization of PBAs electrodes (Wang et al., 2018).

Various studies (You et al., 2014; Hwang et al., 2019; Chen et al., 2020) have performed a consolidated study of the electrochemical performance of different cathode materials. Considerable comparision can be made between the chargedischarge profiles for these materials, in order to draw conclusions about the cathode behavior.

The types of cathodes studied in this section are categorized and summarized according to their performance parameters in Table 1.

Considering negative electrodes, various type of materials such as carbon-based materials, titanates, alloys, and metal oxides/ sulfides can be used in SIB (Yu et al., 2020). Among them carbon based materials offer the best cost and performance correlation. Ji et al. (Hou et al., 2017), categorized carbonaceous materials as an anode under four groups: i) graphite, ii) hard carbon, iii) heteroatom doped carbon and iv) biomass derived carbon 
TABLE 1 | Performance characteristics of cathode materials for organic sodium-ion batteries.

\begin{tabular}{|c|c|c|c|c|c|c|c|}
\hline Cathode type & Structure & Category & Cathode material & Potential (V) & $\begin{array}{c}\text { Discharge } \\
\text { capacity (mAh g-1) }\end{array}$ & $\begin{array}{c}\text { Energy } \\
\text { density (kWh } \\
\left.\mathbf{g}^{-1}\right)\end{array}$ & References \\
\hline \multirow[t]{7}{*}{$\begin{array}{l}\text { Transition metal } \\
\text { oxides }\end{array}$} & \multirow[t]{7}{*}{$\begin{array}{l}\text { Cubic close-packed arrangement with 1D-, } \\
\text { 2D- or 3D-type tunnels }\end{array}$} & P2-layered & $\mathrm{Na}_{2 / 3} \mathrm{Mn}_{1-\mathrm{y}} \mathrm{Mg}_{\mathrm{y}} \mathrm{O}_{2}$ & $1.5-4.0$ & 140 & - & $\begin{array}{l}\text { Clément et al. } \\
\text { (2016) }\end{array}$ \\
\hline & & P2-layered & $\mathrm{Na}_{2 / 3}\left[\mathrm{Mn}_{2 / 3} \mathrm{Ni}_{1 / 3}\right] \mathrm{O}_{2}$ & $2.9-4.0$ & 161 & - & $\begin{array}{l}\text { Lu and Dahn } \\
\text { (2001) }\end{array}$ \\
\hline & & O2-layered & $\mathrm{Na}_{2 / 3}\left[\mathrm{Mn}_{0.8} \mathrm{Ni}_{0.2}\right] \mathrm{O}_{2}$ & $2.0-4.3$ & 162 & - & $\begin{array}{l}\text { Konarov et al. } \\
(2018)\end{array}$ \\
\hline & & O3-layered & $\mathrm{Na}_{0.78} \mathrm{Li}_{0.18} \mathrm{Ni}_{0.25} \mathrm{Mn}_{0.583} \mathrm{O}_{\mathrm{w}}$ & $1.5-4.5$ & 240 & 675 & Liu et al. (2015) \\
\hline & & P2-layered & $\mathrm{Na}_{2 / 3}\left[\mathrm{Mn}_{0.72} \mathrm{Mg}_{0.28}\right] \mathrm{O}_{2}$ & $1.5-4.4$ & $\sim 180$ & - & $\begin{array}{l}\text { Yabuuchi et al. } \\
\text { (2014) }\end{array}$ \\
\hline & & P2-layered & $\mathrm{Na}_{2 / 3} \mathrm{Mn}_{0.7} \mathrm{Zn}_{0.3} \mathrm{O}_{2}$ & $1.5-4.6$ & 190 & - & $\begin{array}{l}\text { Konarov et al. } \\
\text { (2019) }\end{array}$ \\
\hline & & P2-layered & $\mathrm{Na}_{2 / 3} \mathrm{M}_{\mathrm{n} 0.8} \mathrm{Fe}_{0.1} \mathrm{Ti}_{0.1} \mathrm{O}_{2}$ & $2.0-4.0$ & 144.16 & 399.32 & Han et al. (2016) \\
\hline $\begin{array}{l}\text { Transition metal } \\
\text { fluorides }\end{array}$ & Weberite-type & Sodium metal fluorides & $\mathrm{Na}_{2} \mathrm{FeTiF}_{7}$ & 3.26 & 190 & GED 620 & $\begin{array}{l}\text { Euchner et al. } \\
\text { (2019) }\end{array}$ \\
\hline \multirow{5}{*}{$\begin{array}{l}\text { Polyanionic } \\
\text { compounds }\end{array}$} & \multirow{5}{*}{$\begin{array}{l}\text { Olivine structure with rhombohedral R-3 } \\
\text { symmetry }\end{array}$} & Phosphates and NASICON type & $\mathrm{NaFePO}_{4}$ & 3 & 150 & 450 & Hasa et al. (2017) \\
\hline & & & $\mathrm{Na}_{3} \mathrm{~V}_{2}\left(\mathrm{PO}_{4}\right)_{3}$ & 3.3 & 117 & 394 & Guo et al. (2017) \\
\hline & & & $\mathrm{Na}_{3} \mathrm{~V}_{2}\left(\mathrm{PO}_{4}\right)_{2} \mathrm{O}_{2} \mathrm{~F}$ & 3.8 & 128 & 486 & Guo et al. (2017) \\
\hline & & Fluorophosphates & NASICON-type $\mathrm{Na}_{3} \mathrm{~V}_{2}\left(\mathrm{PO}_{4}\right)_{2} \mathrm{~F}_{3}$ & $1.6-4.6$ & 111 & - & Song et al. (2014) \\
\hline & & Sulfates & $\mathrm{Na}_{2} \mathrm{Fe}_{2}\left(\mathrm{SO}_{4}\right)_{3} @ \mathrm{C} @ \mathrm{GO}$ & 3.8 & 107.9 & 400 & Chen et al. (2018) \\
\hline \multirow[t]{5}{*}{$\begin{array}{l}\text { Prussian blue } \\
\text { analogs }\end{array}$} & \multirow[t]{5}{*}{$\begin{array}{l}\text { Face-centered cubic geometry and open- } \\
\text { framework lattice }\end{array}$} & $\begin{array}{l}\text { Binder free cathode - Fe-HCF } \\
\text { NSs@GRs }\end{array}$ & $\begin{array}{l}\text { Sodium iron hexacyanoferrate (Fe- } \\
\text { HCF) }\end{array}$ & $2.0-4.2$ & 110 & - & Luo et al. (2017) \\
\hline & & High-quality PB nanocrystals & $\mathrm{Na}_{0.61} \mathrm{Fe}\left[\mathrm{Fe}(\mathrm{CN})_{6}\right]_{0.94}$ & $4.0-2.7$ & 170 & - & You et al. (2014) \\
\hline & & Ferrocyanide & $\mathrm{Na}_{1.92} \mathrm{Mn}\left[\mathrm{Fe}(\mathrm{CN})_{6}\right]_{0.98}$ & 3.34 & 105.7 & - & Peng et al. (2019) \\
\hline & & Poly (hexaazatrinaphthalene) & PHATN & $1.0-3.5$ & $\begin{array}{l}\text { Reversible capacity } \\
\text { of } 220\end{array}$ & 440 & Mao et al. (2019) \\
\hline & & $\mathrm{C}_{6} \mathrm{R}_{4} \mathrm{O}_{2}$ molecules $(\mathrm{R}=\mathrm{F}, \mathrm{Cl}, \mathrm{Br})$ & Quinone-derivative, $\mathrm{C}_{6} \mathrm{Cl}_{4} \mathrm{O}_{2}$ & $\begin{array}{c}\sim 2.72 \mathrm{~V} \text { vs. } \mathrm{Na} / \\
\mathrm{Na}+\end{array}$ & 161 & 420 & Kim et al. (2015) \\
\hline
\end{tabular}


materials. A conventional graphite anode performs poorly in SIBs. Due to the thermodynamical instability of the sodiated graphite, the formation of these compounds is predicted to be stable only at lower potentials. Since graphite delivers small capacity, hard carbon (HC) is considered as promising material due to a high potential and wider interlayer spacing, which led to a high reversible capacity and excellent cyclability (Nayak et al., 2018). However, there are still several challenges related to the hard carbon (El Moctar et al., 2018). One of them is the rate performance; it shows poor rate capability due to the long diffusion distance. Another one is the low potential plateau, which is close to the sodium plating that threatens battery safety especially at a high rate. Nevertheless some recent (Yu et al., 2020; Ma et al., 2019) studies showed that, it is possible to enhance electrochemical properties of these type of materials by surface modification techniques. Wang et al. showed that sulfur, nitrogen co-doped carbon nanofiber (SNCNF) results with the specific capacity of $247.4 \mathrm{~mA} \mathrm{~h} \mathrm{~g}^{-1}$ (with $98.2 \%$ retention at $0.5 \mathrm{~A} \mathrm{~g}^{-1}$ ) over 600 cycles ( $\mathrm{Yu}$ et al., 2020). Although heteroatom doping of the carbonaceous materials are able to improve sodium intercalation, some other challenges remain open. Li et al. reported that heteroatom doping usually brings a lower internal Coulombic efficiency compared to the original hard carbon which effects the ratio of total cost to discharge energy per cycle life (Chen et al., 2019). As the economic competitiveness is really important for SIBs, novel designs of SIB anodes need to address both performance and cost requirements.

\section{Cost Analysis}

The costs of a BESS play a major role, especially for electric cars, where the cost of a battery pack close to $40-50$ percent of the cost of the vehicle (Curry, 2017). Production costs depend on many factors. e.g., material costs, production equipment, and if it is required, additional technologies (sensors, cooling system, and safety measurements).

Costs of $\mathrm{Na}$ based batteries are believed to be lower than for $\mathrm{Li}$ batteries in the near future. This is not only because the Na the fourth most abundant element on earth but also as $\mathrm{Na}$ salts are more stable, and their preparation is easier than that of Li salts (Zhao et al., 2017). Na-ion batteries utilize the same manufacturing process that LIBs, and to date, there are commercially available sodium-ion batteries. Due to using highly abundant sodium, cobalt-free active materials, inexpensive electrolytes, and on-hand available anode materials, make SIBs very attractive for battery manufacturers in terms of cost savings. Additional cost reduction can be obtained by using an aluminum current collector instead of high-cost copper because an alloying reaction between $\mathrm{Na}$ and Al does not exist (Nayak et al., 2018).

For realistic cost predictions, calculations must be done for a certain battery cell with defined $\mathrm{kWh}$. As sodium has a higher molecular weight $\left(\mathrm{M}_{\mathrm{w}}\right)$ and a larger size than that of lithium (Yabuuchi et al., 2014), the theoretical energy density may decrease, and the cost at the cell level can increase. Another "cost-influencer" in SIBs is the choice of anode. As it was mentioned in the previous section, a conventional LIB anode material graphite is not suitable for SIB due to intercalation problems and a lack of stable $\mathrm{Na}-\mathrm{C}$ compounds. As a result hard carbon can be considered as a performance effective alternative anode material for SIBs (El Moctar et al., 2018). Hard carbon is relatively more expensive than a conventional graphite anode and the challenge associated with the high price can be solved by preparing the hard carbon from environmentally friendly and renewable bio-waste materials. Numerous studies have been performed by researchers around the world to solve the issues as mentioned above of hard carbon, in order to make it more practical (Kim et al., 2018; Irisarri et al., 2018).

Up to date, commercial HC prices $\mathrm{kg}^{-1}$ are not available. But it has been reported that higher price comes from the high-cost precursors (Kim et al., 2018). There are many studies that focus on low-cost/high yield synthesis of $\mathrm{HC}$ via cheaper precursors (e.g., cellulose, corn stalks, phenolic resin) in order to optimize the cost and performance of SIBs (Irisarri et al., 2018). Buchholz et al. used $\$ 15 \mathrm{~kg}^{-1}$ as a price of HC; however, it can be lowered up to $\$ 8 \mathrm{~kg}^{-1}$, considering the efforts are being done to enhance the properties of the hard carbon (Vaalma et al., 2018).

Argonne National Lab's BatPaC model is another commonly applied battery cost model, with specifications for many common cathode chemistries, including SIBs technology. Recently, Buchholz et al. presented a detailed cost analysis for SIBs by using this model (Vaalma et al., 2018). Apart from material costs, they have taken into account many other factors such as battery pack design (including overhead), hardware, target power and energy in order to calculate the cost at system level.

As we mentioned previously, the use of cobalt-free cathode material reduces the cost already very significantly. Current LIBs technology tends to use either cobalt-free cathodes $\left(\mathrm{LiMn}_{2} \mathrm{O}_{4}\right.$ $\mathrm{LiFePO}_{4}$ ) and/or Ni-rich cathodes (NMC 532, NMC 622, NMC 811). That's why future trends for SIBs technology must be considered with a similar type of cathode. If we make a direct comparison between LIBs and SIBs with their $-\mathrm{MnO}_{2}$ cathodes, it is seen that at the cell level LIBs offer $13 \%$ cheaper cost, even positive active material and negative current collector (copper) for LIBs is more expensive than that of SIBs. At system level ( $11.5 \mathrm{kWh}$ battery), this price gap decreases up to $11 \%$.

Detailed material costs for layered oxide cathode based LIBs and SIBs and a calculated total system cost $\left(\$ \mathrm{kWh}^{-1}\right)$ taken from BatPaC model are given in Figure 4 and Table 2.

Another beneficial study was conducted by Peters et al. (2017). By using the same BatPaC model, they have compared layered oxide $\left(\mathrm{Na}_{1.1} \mathrm{Ni}_{0.3} \mathrm{Mn}_{0.5} \mathrm{Mg}_{0.05} \mathrm{Ti}_{0.05} \mathrm{O}_{2}\right)$ SIBs cells with two different LIBs cell chemistries: lithium-nickel-manganesecobalt-oxide cathodes $\left(\mathrm{Li}_{1.05} \mathrm{Ni}_{0.33} \mathrm{Mn}_{0.33} \mathrm{Co}_{0.33} \mathrm{O}_{2} ; \quad \mathrm{NMC111}\right)$ and lithium-iron-phosphate cathodes ( $\mathrm{LiFePO}_{4}$; LFP). According to their calculations, cost $/ \mathrm{kW}^{-1} \mathrm{~h}$ is $\$ 263$ for SIBs, $\$ 270$ for LFP, and $\$ 198$ for NMC111. It is very obvious that SIBs cannot compete with NMC based LIBs. Additionally, one should strongly consider that future designs tend to increase Ni content in the cathode (NMC622, NMC811). As cobalt is a costly raw material, decreasing Co will automatically reduce the cost of the battery while increasing the energy density thanks to high $\mathrm{Ni}$ content. Table 3 summarizes the literature values in terms of battery chemistries and their cost. 


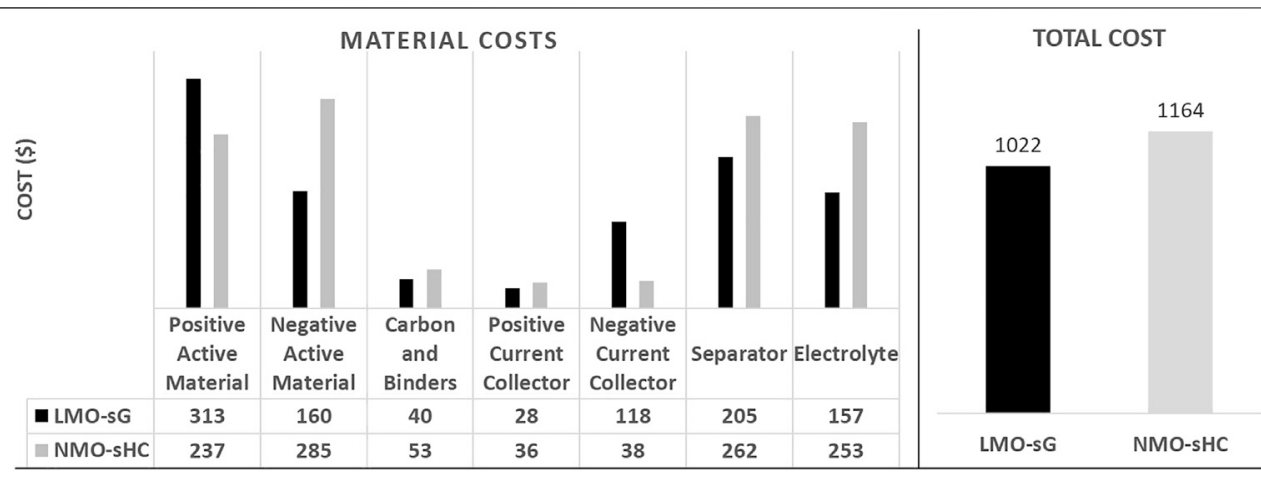

FIGURE 4 | Material costs of layered oxide cathode based lithium-ion batteries and SIBs. Data are redrawn from Vaalma et al. (2018).

TABLE 2 | Total system cost $\left(\$ \mathrm{kWh}^{-1}\right)$ of layered oxide cathode based LIBs and SIBs for $11 \mathrm{kWh}$ systems (Vaalma et al., 2018).

\begin{tabular}{|c|c|c|c|}
\hline & Unit & LMO-sG & NMO-sHC \\
\hline \multicolumn{4}{|l|}{ Materials } \\
\hline Cathode material price & $\$$ & 10.0 & 7.6 \\
\hline Cathode material spec. capacity & $\mathrm{mAh} \mathrm{g}^{-1}$ & 100.0 & 160.0 \\
\hline Cathode material density & $\mathrm{g} \mathrm{cm}^{-3}$ & 4.2 & 4.2 \\
\hline Positive current collector & Metal & Aluminum & Aluminum \\
\hline Anode material price & $\$$ & 15.0 & 15.0 \\
\hline Anode material spec. capacity & $\mathrm{mAh} \mathrm{g}^{-1}$ & 360.0 & 300.0 \\
\hline Anode material density & $\mathrm{g} \mathrm{cm}^{-3}$ & 2.2 & 1.5 \\
\hline Negative current collector & Metal & Copper & Aluminum \\
\hline OCV at $50 \%$ SOC & V & 4.0 & 2.5 \\
\hline \multicolumn{4}{|l|}{ Battery system values } \\
\hline Target power & $\mathrm{kW}$ & 7.0 & 7.0 \\
\hline Approximately, target power for 30 -s pulse & kW & 5.6 & 5.6 \\
\hline Energy & $\mathrm{kWh}$ & 11.5 & 11.5 \\
\hline Modules per battery & - & 2.0 & 2.0 \\
\hline Total number of cells per battery & - & 72.0 & 72.0 \\
\hline Mass & $\mathrm{Kg}$ & 89.5 & 111.6 \\
\hline Volume & L & 51.3 & 73.9 \\
\hline Specific energy density & Wh kg $\mathrm{kg}^{-1}$ & 128.5 & 103.1 \\
\hline Volumetric energy density & $W h L^{-1}$ & 224.1 & 155.7 \\
\hline Price per energy & $\$ \mathrm{kWh}^{-1}$ & 259,2 & 286,9 \\
\hline
\end{tabular}

The best cost/performance relation is given for advanced SIBs, which is designed based on future development predictions. Yet the price per $\mathrm{kWh}$ is still much higher than LIBs.

Apart from research studies, the market analysis also agrees that SIBs do not provide cost advantage compared to LIBs (Frost and Sullivan, 2019a; Frost and Sullivan, 2019b). It has been reported that SIBs may offer better cost if only Li price increases sharply. As it will be discussed in Summary and Outlook, an increase in Li prices depends on reserve depletion, and this will not occur in the near time frame, not probably before 2028 .

\section{EFFECT OF NA-BATTERIES ON CIRCULAR ECONOMY}

\section{Availability of Raw Materials Battery Grade Li vs. Battery Grade $\mathrm{Na}$}

In recent years, many lithium mining projects have been expanded or set up newly, driven by the huge demand of LIBs as it is forecasted for the coming years, mainly based on the expected growth of electromobility (Graedel et al., 2015; Nassar et al., 2015; Roskill, 2019). This led to an increase in the lithium mining capacity by a factor of more than two in the years from 2015 (ca. 269,000 t lithium carbonate, $\mathrm{Li}_{2} \mathrm{CO}_{3}$, equivalent (LCE) to 2018 (ca. 649,000 t LCE. While the utilization rate in 2018 only reached about $60 \%$, the lithium mining capacities are expected to increase further, again by a factor of more than two until 2024, reaching ca. 1,500,000 t LCE per year (Table 4).

Even if the total lithium demand for first use is forecasted to more than triple in the period from 2018 to 2023, reaching 699,000 t LCE per year, the lithium mining capacity can easily

TABLE 3 | Comparison of different type of SIBs and LIBs in terms of their energy densities and costs (Peters et al., 2017; Vaalma et al., 2018).

\begin{tabular}{|c|c|c|c|c|c|}
\hline Battery & Cathode & Anode & Electrolyte & $\begin{array}{l}\text { Energy density } \\
\left(\mathrm{Wh} \mathrm{kg}^{-1}\right)\end{array}$ & $\begin{array}{l}\text { Cost (\$ } \\
\left.k^{-1} h^{-1}\right)\end{array}$ \\
\hline SIB1-1 & $\mathrm{Na}_{1.1} \mathrm{Ni}_{0.3} \mathrm{Mn}_{0.5} \mathrm{Mg}_{0.05} \mathrm{Ti}_{0.05} \mathrm{O}_{2}$ & $\mathrm{HC}$ on Al foil & $\mathrm{NaPF}_{6}$ in ethylene carbonate/dimethyl carbonate & 138.8 & 263 \\
\hline SIB-2 & $\beta-\mathrm{NaMnO}_{2}$ & $\mathrm{HC}$ on $\mathrm{Al}$ foil & $\mathrm{NaPF}_{6}$ in ethylene carbonate/ethyl methyl carbonate & 103.1 & 259.2 \\
\hline SIB-3 & Advanced Na-ion cathode ${ }^{a}$ & Phosphorus HC composite on Al foil & $\mathrm{NaPF}_{6}$ in ethylene carbonate/ethyl methyl carbonate & 152 & 248.5 \\
\hline LIB-1 & $\mathrm{Li}_{1.05} \mathrm{Ni}_{0.33} \mathrm{Mn}_{0.33} \mathrm{Co}_{0.33} \mathrm{O}_{2}$ & Graphite on Cu foil & $\mathrm{LiPF}_{6}$ in ethylene carbonate/dimethyl carbonate & 208 & 198 \\
\hline LIB-2 & $\mathrm{LiFePO}_{4}$ & Graphite on Cu foil & $\mathrm{LiPF}_{6}$ in ethylene carbonate/dimethyl carbonate & 143.1 & 270 \\
\hline LIB-3 & $\mathrm{LiMn}_{2} \mathrm{O}_{4}$ & Graphite on Cu foil & $\mathrm{LiPF}_{6}$ in ethylene carbonate/ethyl methyl carbonate & 128.5 & 286.9 \\
\hline
\end{tabular}

${ }^{a} \mathrm{Na}_{0.76} \mathrm{Mn}_{0.5} \mathrm{~N}_{\mathrm{iO} .3} \mathrm{Fe}_{0.1} \mathrm{Mg}_{0.1} \mathrm{O}_{2}, \mathrm{Na}_{0.6} \mathrm{Ni}_{0.22} \mathrm{Al}_{0.11} \mathrm{Mn}_{0.66} \mathrm{O}_{2}$, etc. 
TABLE 4 | Lithium mining and production capacities for selected years (Roskill, 2019).

\begin{tabular}{|c|c|c|c|c|c|c|c|}
\hline \multirow[t]{2}{*}{ Mine capacity } & Cap. 2015 & Prod. 2015 & Cap. 2018 & Prod. 2018 & Utilization 2018 & Cap. 2024 & Cap. 2028 \\
\hline & t LCE & t LCE & t LCE & t LCE & $\%$ & t LCE & t LCE \\
\hline Total & 269.000 & 186.000 & 645.000 & 398.000 & 61 & $1,498.000$ & $1,543.000$ \\
\hline Thereof brine cap & 130.000 & - & 222.000 & 145.000 & 66 & 493.000 & 537.000 \\
\hline Thereof mineral cap & 139.000 & - & 423.000 & 253.000 & 59 & $1,005.000$ & $1,006.000$ \\
\hline
\end{tabular}

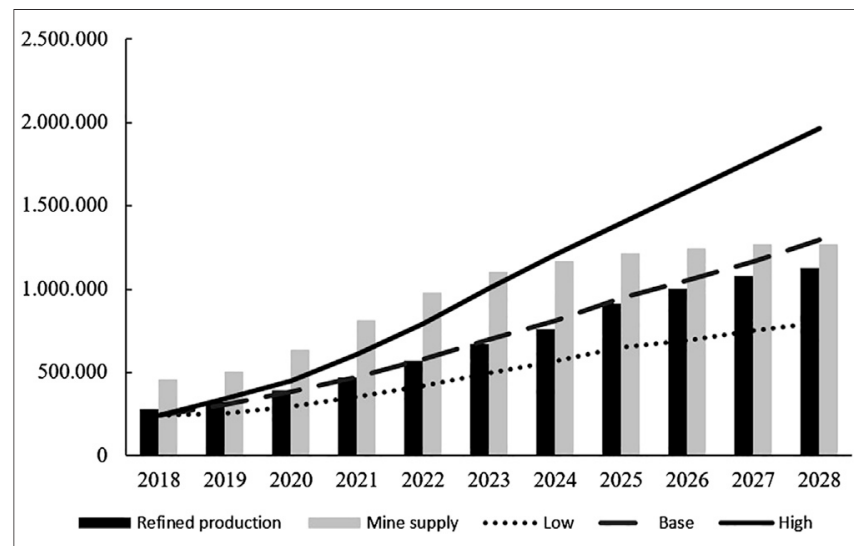

FIGURE 5 | Lithium market balance 2018-2028: base, low, high case demand (LCE t). Data are redrawn from Ref. Roskill (2019).

cover the forecasted demand, probably until 2025, according to our expectations (Figure 5). This led to a decrease in the price of $\mathrm{Li}_{2} \mathrm{CO}_{3}$ and lithium hydroxide monohydrate $(\mathrm{LiOH})$ in the past 2 years, which slows down the expansion of lithium mining capacities. However, most of the projects are not canceled, but are put on hold, so that they can be reactivated if the market demand makes it feasible. Looking further into the future, until 2028, a growing shortage of refined lithium is expected due to further strong growth of the lithium demand, despite the fact that there is no shortage of lithium in general. There areworldwide lithium reserves in the amount of 17 million tons of elemental lithium (Fortier et al., 2018), which is equivalent to about 90 million tons LCE. However, there are some challenges and risks to be tackled: i) The current lithium market is dominated by an oligopoly of the five biggest lithium producers, ii) The lithium supply chain is strongly influenced by Chinese companies, iii) The quality of battery-grade lithium is challenging for lithium producers, especially as the producers must increase the portion of battery-grade lithium from about $40 \%$ in 2018 to about than $90 \%$ in 2028 (Roskill, 2019). Reaching this target under the condition of cost-competitiveness will be challenging.

To conclude, there will be most likely enough lithium to satisfy the market demand for LIBs. However, if the few accessible lithium reserves come under the control of one or a few actors (today more than $70 \%$ of lithium raw material production is under Chinese influence or control), or if the current oligopoly is even more concentrated, and under consideration of the technical challenge to produce battery-grade lithium raw materials, LIBs producers in some countries might experience serious difficulties in getting enough lithium raw materials for a competitive price.
The establishment of cost-effective recycling technologies as a part of a LIBs circular economy, may critically influence this market not only from the point of cost and material availability but also homogeneous access to the resources (Graedel et al., 2011; U. G. Survey, 2015).

Sodium carbonate or soda ash $\left(\mathrm{Na}_{2} \mathrm{CO}_{3}\right)$ is refined from trisodium hydrogendicarbonate dehydrate (trona, $\mathrm{Na}_{2} \mathrm{CO}_{3} \cdot \mathrm{NaHCO}_{3} \cdot 2 \mathrm{H}_{2} \mathrm{O}$ ) (Dai and Chung, 1996). Trona is found in a tremendous amount in seawater (Hwang et al., 2017) and contains over $90 \%$ of a mixture of sodium carbonate and bicarbonate $\left(\mathrm{NaHCO}_{3}\right)$ (Dai and Chung, 1996). The world-leading largest known resources for trona are in Wyoming with 47 billion tons of identified soda ash resources and. It is estimated that worldwide, trona beds contain about 75 billion metric tons of ore, and about 1.8 tons of trona yields 1 ton of $\mathrm{Na}_{2} \mathrm{CO}_{3}$ (USGS National Minerals Information Center, 2020).

As trona is highly soluble in water "monohydrate process" is mainly used to collect $\mathrm{Na}_{2} \mathrm{CO}_{3}$. Solvay announces their position as a "world leader" in soda ash with their $500 \mathrm{kt}$ production capacity. Apart from trona, they also produce synthetic $\mathrm{Na}_{2} \mathrm{CO}_{3}$ by an industrial process which is named as "Solvay ammonia process" (Solvay). However, this process is not advantageous or favorable due to its relatively high production costs and higher environmental impacts (more carbon dioxide release during production) (USGS National Minerals Information Center, 2020).

\section{Cathode Materials}

The material use of currently dominant cell chemistries for Lithium-ion batteries (LIB) is assessed as critical, concerning its supply risk (SR). Cobalt-free battery technologies beyond LIBs, e.g., Li-S or SIBs bear the potential of easing the supply situation for future technologies. The supply risk of resources is predominantly assessed by the methodology introduced by Graedel et al. (2012) and summarized by Benjamin Achzet (2013). Various predefined indicators are analyzed, representing the risk arising from future supply reduction, demand increase market concentration as well as political conditions in resource mining countries. Recent work by Helbig et al. (2018), Wentker et al. (2019) apply the methodology of supply risk evaluation to different battery technologies. Initially, the materials of various cell chemistries are assessed on an element level. Thereupon, the results are aggregated on a battery level on the basis of mass [Helbig et al. used various other aggregation methods (Helbig et al., 2018)]. Hence, the overall supply risk of the assessed cell chemistries equals the weighted average of the supply risk of the contained materials. While Helbig et al. focus on Li-Ion 
TABLE 5 | Supply risk and supply/demand situation of various battery materials

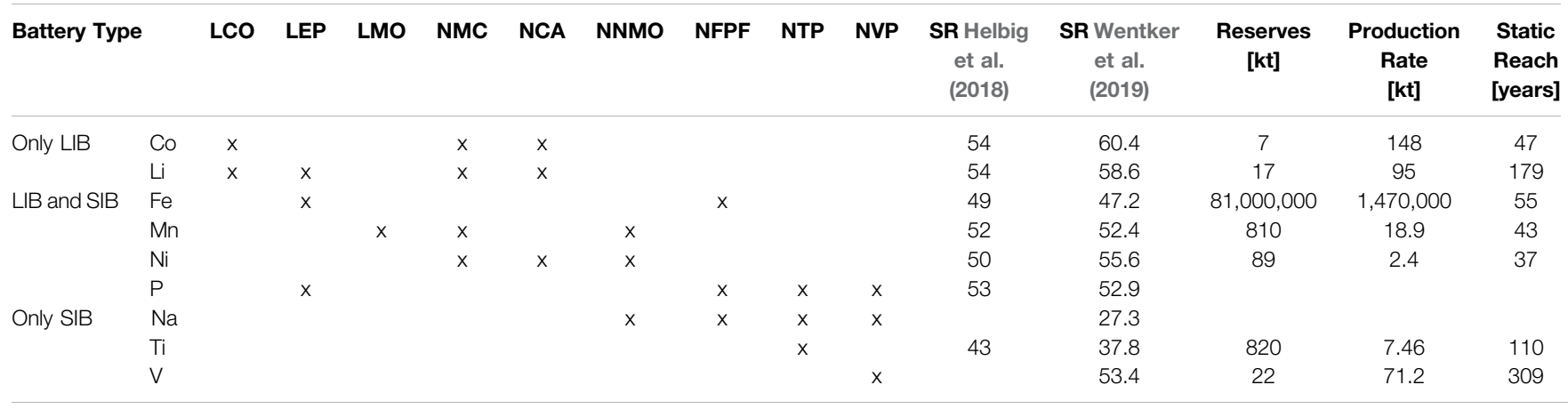

batteries, Wentker et al. include various Na-ion batteries in their evaluation (Helbig et al., 2018; Wentker et al., 2019). Nevertheless, some materials are used in either cathode technology, which is why the results of Helbig et al. are also discussed in this article. Furthermore, it is examined if both articles draw similar conclusions concerning such materials and cell chemistries that are assessed by both.

The results on an element level are summarized in Table 5: Both studies use a scale from 0 to 100 supply risk points, where a score of 100 equals "the highest possible supply risk" for the assessed material. As can be observed, the supply risk scores of the respective materials are in a similar range. Small derivations occur due to different applied weightings (each determined in an analytical hierarchy process) of the indicators and the baseline year of the data used.

Helbig et al. compared different technologies among each other but abstained from making general statements about the criticality of supply. In contrast, Wentker et al. defined a "supply risk threshold" at 50 points. Bypassing this value, the assessed materials and technologies are estimated to be critical concerning their supply situation. According to this classification, cobalt, lithium, manganese, nickel, phosphorus, and vanadium are rated as critical (Helbig et al., 2018). With the exception of manganese (which is marginally beneath the supply risk criticality-threshold defined by the EU) and nickel, this corresponds to the findings of the EU study about critical raw materials (Sun et al., 2019). Graedel et al. also evaluate manganese and nickel as rather not critical concerning the respective supply risk (Graedel et al., 2012). However, it needs to be stated that the demand for nickel will increase significantly due to rising demands for EVs and the simultaneous wider application of nickel-rich cathodes. This and the resource consumption of other future technologies and applications, like for example, solar thermal power plants, wind turbines, superalloys, and others bear the potential of increasing the supply risk of nickel significantly within the next years. Helbig et al. rate phosphorus and manganese with higher criticality scores than nickel, while this is not the case in the evaluation of Wentker et al. From the assessed materials, cobalt and lithium obtain the highest supply risk scores in both researches. In contrast, sodium is scored with the lowest supply risk by far, followed by titanium, which is applied in some versions of SIBs. Sodium is abundant in the earth's crust due to its occurrence as various salts in different minerals and brines.

Table 5 also lists the static reach of the considered materials in order to give an impression about the current supply and demand situation. Neither increases in supply due to recycling and exploration/economical extraction of new reserves, nor future increases in demand are taken into account by the static reach indicator. According to this simplified approach, nickel has the lowest reach in material availability, followed by manganese and cobalt. In contrast to lithium's high supply risk score, which mainly depends on its inability concerning recyclability and substitutability as well as company and country concentration of mine production, the static reach of lithium supply is very uncritical (Sun et al., 2019). This is in consensus with the findings discussed in Battery Grade Li vs. Battery Grade Na.

Table 6 lists the aggregated results for the supply risk of the individual cell chemistries. From the Li-Ion Battery technologies, Helbig et al., as well as Wentker et al. score the LFP cathode with the lowest supply risk (although Helbig et al. distinguish between LFP with graphite- and with lithiumtitanate anodes) (Helbig et al., 2018; Wentker et al., 2019). Homogenous results can also be observed concerning the evaluation of NMC and NCA. Assessed as two of the more critical cell chemistries, both receive similar supply risk scores. The only significant difference between the two articles concerns the LCO cell chemistry. Wentker et al. evaluate it as the most critical while Helbig et al. instead classify the supply risk of LCO in the midst of the assessed cell chemistries. It is noticeable that all Na-Ion Battery technologies are evaluated with lower supply risk scores than Li-Ion Battery technologies. None of the considered cell chemistries containing sodium surpasses the defined criticality threshold of 50 supply risk points. The fact that NNMO and NVP are rated as more critical than NFPF and NTP are due to the supply risks of the contained nickel and vanadium. Furthermore, manganese increases the supply risk of NNMO significantly. The use of phosphorus has a considerable impact on the supply risk of NFPF, NTP, and NVP. The change of cell chemistry often is accompanied with variations in material composition of various other components of battery systems. The impact of varying materials for anodes is shown by Helbig et al. for LFP. 
TABLE 6 | Supply risk of various battery technologies/cell chemistries.

\begin{tabular}{|c|c|c|c|}
\hline Battery technology & Cathode & SR Helbig et al. (2018) & SR Wentker et al. (2019) \\
\hline \multirow[t]{6}{*}{ LIB } & LCO & 47 & 60.2 \\
\hline & LFP-C & 49 & 49.9 \\
\hline & LFP-LTO & 45 & - \\
\hline & LMO & 48 & 52.8 \\
\hline & NMC & 50 & 56.4 \\
\hline & NCA & 49 & 56.4 \\
\hline \multirow[t]{4}{*}{ SIB } & NNMO & - & 46.3 \\
\hline & NFPF & - & 41.6 \\
\hline & NTP & - & 43.3 \\
\hline & NVP & - & 46.4 \\
\hline
\end{tabular}

Wentker et al. also assess the environmental impact score of the considered cell chemistries. The environmental impact score (EI) is measured by taking various criteria for the dimensions "damage to the ecosystem" and "damage to human health" into account. According to Wentker et al., the EI of Na-Ion Technology is significantly lower than for currently predominant cell chemistries (NCA, NMC). This is partly due to the use of lithium and cobalt, but more significantly due to the environmental impact of nickel production (especially in nickelrich cathode NMC as well as NCA). The impact of nickel in NNMO is compensated by the very low environmental impact of the remaining cathode materials (manganese and sodium).

In summary, NIB technologies are more favorable compared to LIB technologies concerning the supply risk of their contained materials, mainly due to cobalt- and lithium-free cathodes in NaIon batteries. However, nickel, which is also used in NNMO has a considerable impact on the supply risk of battery technologies. This is why the supply risk of Li-Ion batteries with high nickel content (e.g., NMC811) does not significantly differ from NMC111, although minimizing the amount of contained cobalt. Considering material aspects, the advantage of $\mathrm{Na}$-Ion over Li-Ion batteries is even more obvious by taking the environmental impacts (EI) of material supply into account.

\section{Recycling Forecast for Lithium}

Recycling of used LIBs is a key element to keep materials in a closed-loop system, which reduces the demand for primary raw materials in production and potential supply risk of critical raw materials. Extension of LIB lifetime in second life applications, like decentralized energy storage is desirable. However, even these battery systems must ultimately be recycled at the end of their life in order to establish a circular economy.

Since the concentration of lithium in used LIBs (ca. 5-7 wt\%) is higher than in natural resources, LIBs can be considered as a large reserve of lithium (Shin et al., 2005; Yao et al., 2018; Liu et al., 2019). Nevertheless, the main research focus in the field of recycling LIBs lies especially in the recovery of cobalt due to economic reasons (Liu et al., 2019). From both an ecological and socio-economic point of view, the recovery of lithium plays an important role, even if, as described above, the reserves will not run out until 2030. On the one hand, the extraction of lithium is associated with high water consumption and the resulting ecological effects. On the other hand, Europe, in particular, is dependent on the supply of lithium from a few countries worldwide.

In general, there are two different recycling methods for the recovery of lithium from LIBs: pyrometallurgical and hydrometallurgical methods, as shown in Figure 6 (Mossali et al., 2020). Other forms such as repair and regeneration of cathode materials using solid-phase sintering are not considered in this work. In the following, the advantages and disadvantages of both recycling methods and their process steps are described briefly. The recovery of lithium by the two recycling methods is of particular interest in this work.

As shown in Figure 2, the used LIBs are discharged prior to the actual recycling to prevent short-circuiting and self-ignition of the battery systems (Hanisch et al., 2015; Li et al., 2018b; Mossali et al., 2020). This is usually done using salt-saturated solutions with the drawback that lithium incorporated in the electrolyte is lost in this process step (Chen et al., 2019; Han et al., 2016).

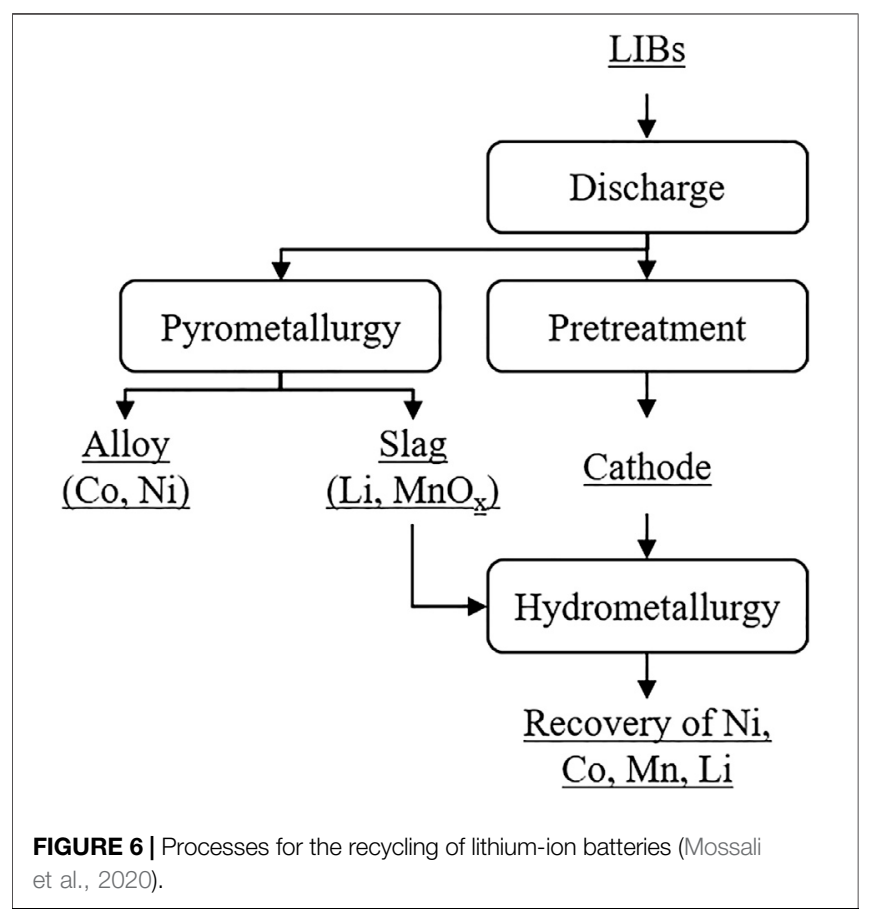




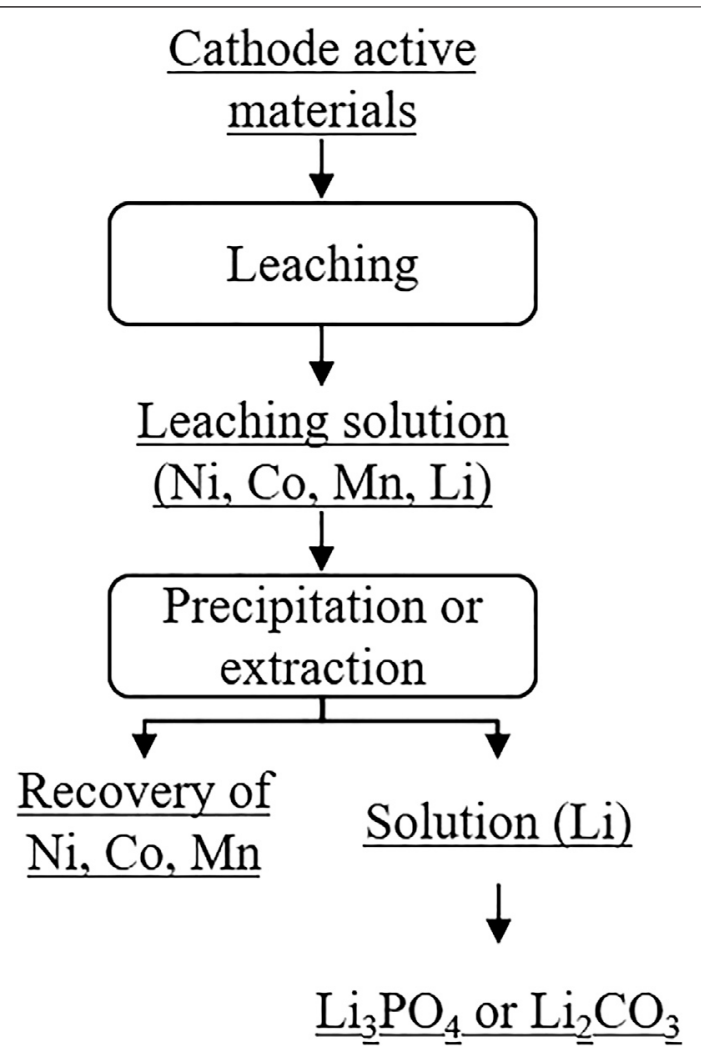

FIGURE 7 | Recovery of active cathode materials from lithium-ion batteries (Liu et al., 2019).

Without further treatment, the discharged LIBs can be used as input for pyrometallurgical recycling.

Pyrometallurgical recycling is the most mature battery recycling technology and used to extract target metals by high temperatures, which leads to physical and chemical transformations. The simple operation, which is also easy to scale up, and the ability to recycle different battery chemistries simultaneously are one of the main advantages of this recycling method (Baltac and Slater, 2019; Fan et al., 2020). In pyrometallurgical recycling, the LIBs are fed to a hightemperature shaft furnace together with a slag forming agent (Gaines, 2014; Harper et al., 2019). Redox reactions are activated to smelt and purify valuable metals (Lv et al., 2018; Zheng et al., 2018; Velázquez-Martínez et al., 2019). The output of the pyrometallurgical process is a metallic alloy fraction containing, e.g., $\mathrm{Ni}$ and $\mathrm{Co}$, slag, and gases (Harper et al., 2019). To avoid the release of potentially toxic by-products, gas clean-up steps are necessary (Gaines, 2014). The resulting furnace slag consists of ashes and burnt components, primarily containing aluminum, lithium, and other materials (Shin et al., 2005; Yao et al., 2018; Liu et al., 2019). The recovery of lithium from the slag is possible using further treatment in the form of hydrometallurgical recycling (see Figure 6). However, this is not economically viable and, therefore, usually not performed (Gaines, 2018; Mossali et al., 2020). Instead, the slag can be reused, e.g., as a cement additive (Gaines, 2018).
Despite disadvantages of the pyrometallurgical process, like high capital costs, production of toxic gases, high-energy consumption, and a limited number of reclaimed materials, pyrometallurgical recycling remains a frequently used, economical process for the extraction of high-value transition metals such as cobalt and nickel (Joulié et al., 2014; Gaines, 2014; Chen et al., 2015; Harper et al., 2019; Mossali et al., 2020).

Hydrometallurgical recycling of active cathode materials consists of leaching, precipitation and/or solvent extraction, as shown in Figure 4 (Liu et al., 2019). The main operating parameters of this recycling method are temperature, acid and reducing agent concentration and species, reaction time, and solid/liquid ratio (Li et al., 2018a; Harper et al., 2019; Mossali et al., 2020). In contrast to pyrometallurgical recycling, the LIBs receive pre-treatment depending on, e.g., cell chemistry and target materials, before they are hydrometallurgically recycled in order to increase recycling efficiency (Baltac Slater, 2019; Mossali et al., 2020). The pre-treatment includes different processes such asmechanical separation, thermal processes, dissolution processes, and mechanochemical methods(Lv et al., 2018; Zheng et al., 2018; Mossali et al., 2020). After the pretreatment, the leaching, i.e., the dissolution of the target materials by leaching reagents, takes place. Mainly the leaching reagents include inorganic acids, organic acids, and alkaline solutions (Liu et al., 2019). The output is a leaching solution containing metals like Ni, Co, Mn, and Li. Trough precipitation and/or solvent extraction, these metals can be separated from the solution. For economic reasons, research has mainly focused on the separation of $\mathrm{Ni}, \mathrm{Co}$, and $\mathrm{Mn}$ from the leaching solution, the recovery of lithium in contrast, is of lesser importance. As shown in Figure 7, the recovery of lithium in the form of $\mathrm{Li}_{3} \mathrm{PO}_{4}$ or $\mathrm{Li}_{2} \mathrm{CO}_{3}$ is usually one of the last process. (Liu et al., 2019). Since the loss of lithium is inevitable and accumulated during the separation of $\mathrm{Ni}, \mathrm{Co}$, and $\mathrm{Mn}$ from the leaching solution, the recycling efficiency of lithium depends on the previous process steps.

In general, the main advantages of hydrometallurgical processes compared with pyrometallurgical processes are higher recovery efficiency of valuable metals, especially regarding lithium, lower energy consumption, less production of toxic gases, and lower capital costs (Lv et al., 2018; Fan et al., 2020; Mossali et al., 2020). The main drawbacks of using hydrometallurgical processes for LIBs recycling are high dependency on pre-treatments and used technologies, emissions associated with the used chemicals, and difficulty to process different battery chemistries at once (Baltac and Slater, 2019; Mossali et al., 2020). This is because each recycling sequence has to be optimized for certain battery chemistry to ensure a high recovery of materials and favorable economics (Baltac and Slater, 2019). Hydrometallurgical recycling allows a recovery rate of around $95 \%$ regarding $\mathrm{Ni}$ and $\mathrm{Co}$ as salts, while $\mathrm{Cu}$ can be recovered up to $100 \%$ and $\mathrm{Li}$ by around $90 \%$. To achieve these high rates, the leaching processes are usually tailored for specific battery chemistries, and extensive pre-treatment processes are necessary. Using hydrometallurgical recycling after the pyrometallurgy process a cost-intensive recovery of about $50-60 \%$ of $\mathrm{Li}$ is possible (Fan et al., 2020; Frost and Sullivan, 2020). In the future, hydrometallurgical recycling processes require an efficient and more rapid removal of impurities to increase the 
purity of the recovered materials (Fan et al., 2020; Frost and Sullivan, 2020). Furthermore, new combinations of pyrometallurgical recycling at lower temperatures and acid/ alkaline free hydrometallurgical recycling, such as vacuum carbothermal reduction and sulfation roasting, seem promising and require future research and industrial implementation (Liu et al., 2019).

Research of Liu et al. shows that recovery of lithium on an industrial scale has so far played only a minor role. Currently, only two out of fourteen analyzed recycling processes for LIBs from different companies recover lithium (Liu et al., 2019). From an economic point of view, the recovery of lithium is currently not viable. Instead, the focus is on the recovery of the more expensive metals: cobalt, nickel (Swain, 2017).

Little information was found about recycling strategies for SIBs. This is due to the non-existence of relevant amounts of EoL-Na-Ion batteries. However, one part of the agenda of the ongoing NAIMA project is to develop a "sustainable and cost-efficient recycling process for SIBs" (European Comission, 2019). Furthermore, the Association of European Automotive and Industrial Battery Manufacturers describes sodium-nickel chloride batteries as "fully recyclable within existing industries for the production of stainless steel and road paving" (Association of European Automotive and Industrial Battery Manufacturers). Although only on a laboratory scale, Liu et al. recently developed a design-for-recycling sodium-ion batteries. The recycling of this battery resulted in a recycling efficiency of more than $98 \%$ concerning its solid components (Liu et al., 1965). The phase of product design is also highlighted by Hirsh et al. As manufacturers for SIBs are at the beginning of upscaling their production, they are expected to be more flexible in incorporating methods of sustainable product design than established LIBs manufacturers. Also, traceability concerning material composition is seen as an important aspect for the future recycling of SIBs. The need for information transfer throughout the whole supply chain is intensified due to the expected main application of SIBs as stationary storage batteries and the associated lifespan (Hirsh et al., 2020).

\section{SUMMARY AND OUTLOOK}

Although SIB technology and its manufacturing is already at the commercialization level, so far it has found little commercial application possibilities. SIBs use the same manufacturing process as LIBs, which is a great advantage for manufacturers. Costdriven advantages of SIBs are sustainable and cheap cathode materials $\left(\mathrm{NaCO}_{3}\right.$, cobalt-free active materials) as well as the use of aluminum current collectors for both negative and positive electrodes. However, as explained in the previous chapters, these

\section{REFERENCES}

Adelhelm, P., Hartmann, P., Bender, C. L., Busche, M., Eufinger, C., and Janek, J. (2015). From lithium to sodium: cell chemistry of room temperature sodiumair and sodium-sulfur batteries. Beilstein J. Nanotechnol. 6, 1016-1055. doi:10. 3762/bjnano.6.105 advantages are not enough to reduce battery cost. Additionally, the specific energy density of today's SIBs is also not higher than LIBs.

An innovative cell design strategy for these batteries is indispensable to balance both high energy density and the decrease in total battery cost. According to market reports SIBs technology can reach to more competitive level after 2025, especially for large-scale energy storage systems.

After 2025 the required battery capacity for EV market is 1,559 GWh (Automotive Competence Center \& Forschungsgesellschaft Kraftwahrwesen mbH Aachen, 2018). As a result a growing shortage of refined lithium is expected after 2028 due to further strong growth of the lithium demand. This demand will mainly consist of battery grade lithium for which the proportion is expected to increase from $40 \%$ in 2018 to about $90 \%$ in 2028 . Reaching this target under the condition of cost-competitiveness will be challenging. This implies that the use of SIBs in parallel to LIBs for stationary and short lifetime electromobility applications (E-bikes, e-scooters) will definitely decrease the pressure on lithium supply chain.

Moreover, today's lithium recycling technology is highly costly, and battery manufacturing costs must include recycling costs. So far, there are no such cost studies concerning recycling. Last but not least, it is known that an EV with LIBs technology generates more $\mathrm{CO}_{2}$ emissions during production than a vehicle with a combustion engine, due to the highly energy-consuming production of LIBs and their raw materials such as battery-grade lithium. As battery-grade sodium can be extracted from seawater and produced relatively easier than lithium, these batteries can be assumed more environmentally friendly.

There is no doubt that the competition between LIBs and SIBs will continue. However, the major advancement toward SIBs will be achieved by introducing cost-efficient new materials and new cell concepts.

\section{AUTHOR CONTRIBUTIONS}

The authors confirm contribution to the paper as follows: study conception and design: $\mathrm{DK}, \mathrm{KB}$, and $\mathrm{ZB}$; data collection, analysis and interpretation of results, and draft manuscript preparation: DK, SS, SK, JK, AK, FS, RM, MW, ZB, and KB. All authors reviewed the results and approved the final version of the manuscript.

\section{ACKNOWLEDGMENTS}

This research was conducted within the scope of the project "DigiBattPro 4.0 BW". The authors gratefully acknowledge the financial support of the Ministry of Economic Affairs, Labor and Housing Baden-Württemberg.

Ahmadi, L., Young, S. B., Fowler, M., Fraser, R. A., and Achachlouei, M. A. (2017). A cascaded life cycle: reuse of electric vehicle lithium-ion battery packs in energy storage systems. Int. J. Life Cycle Assess. 22 (1), 111-124. doi:10.1007/ s11367-015-0959-7

Al-Thyabat, S., Nakamura, T., Shibata, E., and lizuka, A. (2013). Adaptation of minerals processing operations for lithium-ion (LiBs) and nickel metal hydride (NiMH) batteries recycling: critical review. Miner. Eng. 45, 4-17. doi:10.1016/j.mineng.2012.12.005 
Ambrose, H., and Kendall, A. (2020a). Understanding the future of lithium: Part 1, resource model. J. Ind. Ecol. 24 (1), 80-89. doi:10.1111/jiec.12949

Ambrose, H., and Kendall, A. (2020b). Understanding the future of lithium: Part 2, temporally and spatially resolved life-cycle assessment modeling. J. Ind. Ecol. 24 (1), 90-100. doi:10.1111/jiec.12942

Association of European Automotive and Industrial Battery Manufacturers. Sodium based battery technologies. Available at: https://www.eurobat.org/ batteries-contribution/battery-technologies/sodium-based (Accessed August, 2019).

Automotive Competence Center \& Forschungsgesellschaft Kraftwahrwesen mbH Aachen (2018). E-mobility index 2018. Roland Berger.

Baltac, S., and Slater, S. (2019). Batteries on wheels: the role of battery electric cars in the EU power system and beyond. Element Energy.

Barker, J. (2017). "Progress in the commercialization of faradion's Na-ion battery technology," 4th international conference on sodium batteries, Tokyo, Japan, November 28-30, 2017.

Bauer, A., Song, J., Vail, S., Pan, W., Barker, J., and Lu, Y. (2018). The scale-up and commercialization of nonaqueous $\mathrm{Na}$-ion battery technologies. Adv. Energy Mater. 8 (17), 1702869. doi:10.1002/aenm.201702869

Benjamin Achzet, C. H. (2013). "How to evaluate raw material supply risks-an overview. Resour. Pol. 38 (4), 435-447. doi:10.1016/j.resourpol.2013.06.003

Bin, D., Wang, F., Tamirat, A. G., Suo, L., Wang, Y., Wang, C., et al. (2018). Progress in aqueous rechargeable sodium-ion batteries. Adv. Energy Mater. 8 (17), 1703008. doi:10.1002/aenm.201703008

Chen, M., Cortie, D., Hu, Z., Jin, H., Wang, S., Gu, Q., et al. (2018). A novel graphene oxide wrapped $\mathrm{Na} 2 \mathrm{Fe} 2$ (SO 4 ) 3/C cathode composite for long life and high energy density sodium-ion batteries. Adv. Energy Mater. 8 (27), 1800944. doi:10.1002/aenm.201800944

Chen, M., Hua, W., Xiao, J., Cortie, D., Chen, W., Wang, E., Hu, Z., et al. (2019). NASICON-type air-stable and all-climate cathode for sodium-ion batteries with low cost and high-power density. Nat. Commun. 10 (1), 1-11. doi:10.1038/ s41467-019-09170-5

Chen, M., Zhang, Y., Xing, G., and Tang, Y. (2020). Building high power density of sodium-ion batteries: importance of multidimensional diffusion pathways in cathode materials. Front. Chem. 8, 152. doi:10.3389/fchem.2020.00152

Chen, T., Jin, Y., Lv, H., Yang, A., Liu, M., Chen, B., et al. (2020). Applications of lithium-ion batteries in grid-scale energy storage systems. Trans. Tianjin Univ. 26 (3), 208-217. doi:10.1007/s12209-020-00236-w

Chen, X., Chen, Y., Zhou, T., Liu, D., Hu, H., and Fan, S. (2015). Hydrometallurgical recovery of metal values from sulfuric acid leaching liquor of spent lithium-ion batteries. Waste Manag. 38, 349-356. doi:10. 1016/j.wasman.2014.12.023

Chen, X., Zheng, Y., Liu, W., Zhang, C., Li, S., and Li, J., (2019). "High-performance sodium-ion batteries with a hard carbon anode: transition from the half-cell to full-cell perspective. Nanoscale 11 (46), 22196-22205. doi:10.1039/C9NR07545C

Clément, R. J., Billaud, F., Armstrong, A. R., Singh, G., Rojo, T., Brucebd, P. G., et al. (2016). Structurally stable Mg-doped P2-Na2/3Mn1-yMgyO2 sodium-ion battery cathodes with high rate performance: insights from electrochemical, NMR and diffraction studies. Energy Environ. Sci. 9 (10), 3240-3251. doi:10. 1039/C6EE01750A

Cole, W. J., and Frazier, A. (2019). Cost projections for utility-scale battery storage. Golden, CO: NREL.

Curry, C. (2017). Lithium-ion battery costs \& market. Bloomberg- New Energy Finance.

Dai, Q., and Chung, K. H. (1996). Trona mineral grade sodium carbonate as A process aid for the hot water process. J. Can. Petrol. Technol. 35 (1). doi:10.2118/ 96-01-08

Delmas, C. (2018). Sodium and sodium-ion batteries: 50 years of research. $A d v$. Energy Mater. 8 (17), 1703137. doi:10.1002/aenm.201703137

Deng, J., Luo, W. B., Lu, X., Yao, Q., Wang, Z., Liu, H. K., et al. (2018). High energy density sodium-ion battery with industrially feasible and air-stable O3-type layered oxide cathode. Adv. Energy Material. 8 (5), 1701610. doi:10.1002/aenm. 201701610

Ding, Y., Cano, Z. P., Yu, A., Lu, J., and Chen, Z. (2019). Automotive Li-ion batteries: current status and future perspectives. Electrochem. Energ. Rev. 2 (1), 1-28. doi:10.1007/s41918-018-0022-z

Dolega, P. (2019). Gigafactories für Lithium-Ionen-Zellen, Rohstoffbedarfe für die globale Elektromobilität bis 2050. Darmstadt: Öko-Institut e-V.
El Moctar, I., Ni, Q., Bai, Y., Wu, F., and Wu, C. (2018). Hard carbon anode materials for sodium-ion batteries. Funct. Mater. Lett. 11 (6), 1830003. doi:10. $1142 /$ S1793604718300037

Ellis, B. L., and Nazar, L. F. (2012). Sodium and sodium-ion energy storage batteries. Curr. Opin. Solid State Mater. Sci. 16 (4), 168-177. doi:10.1016/j. cossms.2012.04.002

Etacheri, V., Marom, R., Elazari, R., Salitra, G., and Aurbach, D. (2011). Challenges in the development of advanced Li-ion batteries: a review. Energy Environ. Sci. 4 (9), 3243. doi:10.1039/clee01598b

Euchner, H., Clemens, O., and Reddy, M. A. (2019). Unlocking the potential of weberite-type metal fluorides in electrochemical energy storage. Npj Comput Mater 5 (1), 1-10. doi:10.1038/s41524-019-0166-3

European Comission (2019). Na-ion materials as essential components to manufacture robust battery cells for non.automotive applications: NAIMA Project- H2020. Available at: https://cordis.europa.eu/project/id/875629 (Accessed August, 2019).

Fan, E., Li, L., Wang, Z., Lin, J., Huang, Y., Yao, Y., et al. (2020). Sustainable recycling technology for Li-ion batteries and beyond: challenges and future prospects. Chem. Rev. 120 (14), 7020-7063. doi:10.1021/acs.chemrev.9b00535

Fortier, S. M., Hammarstrom, J. H., Ryker, S. J., Day, W. C., and Seal, R. R. (2018). U.S. Geological Survey, 806 "Mining Engineering2019-USGS Critical Minerals Review. U.S. Department of Commerce.

Frost and Sullivan (2019a). Disruptive battery storage technologies: novel battery technologies beyond lithium-ion chemistry are expected to disrupt the battery market in the next decade. Santa Clara: Frost\&Sullivan.

Frost and Sullivan (2019b). Global Li-ion batteries market, forecast to 2025. Santa Clara: Frost\&Sullivan.

Frost and Sullivan (2020). Managing end-of-life Li-ion batteries: battery recycling technologies: innovative technologies for the recovery and reuse of valuable metals from end-of-life lithium-ion batteries. D952-TV.

Gaines, L. (2014). The future of automotive lithium-ion battery recycling: charting a sustainable course. Sustainable Material. Technolo. 1-2, 2-7. doi:10.1016/j. susmat.2014.10.001

Gaines, L. (2018). Lithium-ion battery recycling processes: research towards a sustainable course. Sustainable Material. Technol. 17, e00068. doi:10.1016/j. susmat.2018.e00068

Graedel, T. E., Allwood, J., Birat, J.-P., Reck, B. K., Sibley, S. F., Sonnemann, G., et al. (2011). UNEP (2011) Recycling rates of metals - a status report, A report of the working group on the global metal flows to the international resource panel.

Graedel, T. E., Barr, R., Chandler, C., Chase, T., Choi, J., Christoffersen, L., et al. (2012). Methodology of metal criticality determination. Environ. Sci. Technol. 46 (2), 1063-1070. doi:10.1021/es203534z

Graedel, T. E., Harper, E. M., Nassar, N. T., and Reck, B. K. (2015). On the materials basis of modern society. Proc. Natl. Acad. Sci. U.S.A. 112 (20), 6295-6300. doi:10.1073/pnas.1312752110

Guo, J.-Z., Wang, P. F., Wu, X. L., Zhang, X. H., Yan, Q., Chen, H., et al. (2017). High-energy/power and low-temperature cathode for sodium-ion batteries: in situ XRD study and superior full-cell performance. Adv. Material. (Deerfield Beach, Fla.) 29, 33. doi:10.1002/adma.201701968

Guo, S., Yu, H., Jian, Z., Liu, P., Zhu, Y., Guo, X., et al. (2014). A high-capacity, lowcost layered sodium manganese oxide material as cathode for sodium-ion batteries. ChemSusChem 7 (8), 2115-2119. doi:10.1002/cssc.201402138

Habib, A., and Sou, C. (2018). Analytical review on the trends and present situation of large-scale sustainable energy storage technology. Eur. J. Sustainable Dev. Res. 2 (3). doi: $10.20897 /$ ejosdr/86200

Han, M. H., Gonzalo, E., Sharma, N., López del Amo, J. M., Armand, M., Avdeev, M., et al. (2016). High-performance P2-phase Na 2/3 Mn 0.8 Fe 0.1 Ti 0.1 O 2 cathode material for ambient-temperature sodium-ion batteries. Chem. Mater. 28 (1), 106-116. doi:10.1021/acs.chemmater.5b03276

Hanisch, C., Loellhoeffel, T., Diekmann, J., Markley, K. J., Haselrieder, W., and Kwade, A. (2015). Recycling of lithium-ion batteries: a novel method to separate coating and foil of electrodes. J. Clean. Prod. 108, 301-311. doi:10.1016/j. jclepro.2015.08.026

Harper, G., Sommerville, R., Kendrick, E., Driscoll, L., Slater, P., Stolkin, R., et al. (2019). Recycling lithium-ion batteries from electric vehicles. Nature 575 (7781), 75-86. doi:10.1038/s41586-019-1682-5

Hasa, I., Passerini, S., and Hassoun, J. (2017). Toward high energy density cathode materials for sodium-ion batteries: investigating the beneficial effect of 
aluminum doping on the P2-type structure. J. Mater. Chem. 5 (9), 4467-4477. doi:10.1039/C6TA08667E

Helbig, C., Bradshaw, A. M., Wietschel, L., Thorenz, A., and Tuma, A. (2018). Supply risks associated with lithium-ion battery materials. J. Clean. Prod. 172, 274-286. doi:10.1016/j.jclepro.2017.10.122

Hirsh, H. S., Li, Y., Tan, D. H. S., Zhang, M., Zhao, E., and Meng, Y. S. (2020). Sodium-Ion batteries paving the way for grid energy storage. Adv. Energy Material. 10, 32. doi:10.1002/AENM.22001274

Hou, H., Qiu, X., Wei, W., Zhang, Y., and Ji, X. (2017). Carbon anode materials for advanced sodium-ion batteries. Adv. Energy Mater. 7 (24), 1602898. doi:10. 1002/aenm.201602898

Hwang, J.-Y., Myung, S.-T., and Sun, Y.-K. (2017). Sodium-ion batteries: present and future. Chem. Soc. Rev. 46 (12), 3529-3614. doi:10.1039/ C6CS00776G

Hwang, J.-Y., Kim, J., Yu, T.-Y., and Sun, Y.-K. (2019). "A new P2-type layered oxide cathode with extremely high energy density for sodium-ion batteries. Adv. Energy Mater. 9 (15), 1803346. doi:10.1002/aenm.201803346

Irisarri, E., Tennison, S., Ghimbeu, C., Gorka, J., Vix, C., Ponrouch, A., et al. (2018). Optimization of large scale produced hard carbon performance in Na-ion batteries: effect of precursor, temperature and processing conditions. J. Electrochem. Soc. 165 (16), A4058-A4066. doi:10.1149/2. 1171816jes

Joulié, M., Laucournet, R., and Billy, E. (2014). Hydrometallurgical process for the recovery of high value metals from spent lithium nickel cobalt aluminum oxide based lithium-ion batteries. J. Power Sources 247, 551-555. doi:10.1016/j. jpowsour.2013.08.128

Kang, W., Zhang, Z., Lee, P. K., Ng, T. W., Li, W., Tang, Y., et al. (2015). Copper substituted P2-type Na0.67CuxMn1-xO2: a stable high-power sodium-ion battery cathode. J. Mater. Chem. 3 (45), 22846-22852. doi:10.1039/ C5TA06371J

Kim, H., Eon Kwon, J., Lee, B., Hong, J., Lee, M., Young Park, S., et al. (2015). High energy organic cathode for sodium rechargeable batteries. Chem. Mater. 27 (21), 7258-7264. doi:10.1021/acs.chemmater.5b02569

Kim, Y., Kim, J.-K., Vaalma, C., Bae, G. H., Kim, G.-T., Passerini, S., and Kim, Y. (2018). Optimized hard carbon derived from starch for rechargeable seawater batteries. Carbon 129, 564-571. doi:10.1016/j.carbon.2017.12.059

Konarov, A., Choi, J. U., Bakenov, Z., and Myung, S.-T. (2018). Revisit of layered sodium manganese oxides: achievement of high energy by $\mathrm{Ni}$ incorporation. J. Mater. Chem. 6 (18), 8558-8567. doi:10.1039/C8TA02067A

Konarov, A., Jae Kim, H., Jo, J. H., Voronina, N., Lee, Y., Bakenov, Z., et al. (2020). High-Voltage oxygen-redox-based cathode for rechargeable sodium-ion batteries. Adv. Energy Mater. 10 (24), 2001111. doi:10.1002/ aenm.202001111

Konarov, A., Jo, J. H., Choi, J. U., Bakenov, Z., Yashiro, H., Kim, J., and Myung, S.-T. (2019). Exceptionally highly stable cycling performance and facile oxygen-redox of manganese-based cathode materials for rechargeable sodium batteries. Nanomater. Energy 59, 197-206. doi:10.1016/j.nanoen. 2019.02.042

Landa-Medrano, I., Li, C., Ortiz-Vitoriano, N., Ruiz de Larramendi, I., Carrasco, J., and Rojo, T. (2016). Sodium-oxygen battery: steps toward reality. J. Phys. Chem. Lett. 7 (7), 1161-1166. doi:10.1021/acs.jpclett.5b02845

Li, L., Biana, Y., Zhanga, X., Guanc, Y., Fana, E., Wu, F., et al. (2018a). Process for recycling mixed-cathode materials from spent lithium-ion batteries and kinetics of leaching. Waste Manag. 71, 362-371. doi:10.1016/j.wasman.2017. 10.028

Li, L., Li, L., Zhang, X., Li, M., Chen, R., Wu, F., et al. (2018b). The recycling of spent lithium-ion batteries: a review of current processes and technologies. Electrochem. Energ. Rev. 1 (4), 461-482. doi:10.1007/ s41918-018-0012-1

Li, L., Lu, Y., Zhang, Q., Zhao, S., Hu, Z., and Chou, S.-L. (2019). Recent progress on layered cathode materials for nonaqueous rechargeable magnesium batteries. Small e1902767. doi:10.1002/smll.201902767

Liu, B., Zhang, J.-G., and Xu, W. (2018). Advancing lithium metal batteries. Joule 2 (5), 833-845. doi:10.1016/j.joule.2018.03.008

Liu, C., Lin, J., Cao, H., Zhang, Y., and Sun, Z. (2019). Recycling of spent lithiumion batteries in view of lithium recovery: a critical review. J. Clean. Prod. 228, 801-813. doi:10.1016/j.jclepro.2019.04.304
Liu, H., Xu, J., Ma, C., and Meng, Y. S. (2015). A new O3-type layered oxide cathode with high energy/power density for rechargeable Na batteries. Chem. Commun. 51 (22), 4693-4696. doi:10.1039/c4cc09760b

Liu, T., Zhang, Y., Chen, C., Lin, Z., Zhang, S., and Lu, J. (1965). Sustainabilityinspired cell design for a fully recyclable sodium ion battery. Nat. Commun. 10, 1. doi:10.1038/s41467-019-09933-0

Liu, Y., He, P., and Zhou, H. (2018). Rechargeable solid-state Li-air and Li-S batteries: materials, construction, and challenges. Adv. Energy Mater. 8 (4), 1701602. doi:10.1002/aenm.201701602

Lu, Z., and Dahn, J. R. (2001). In situ X-ray diffraction study of P 2 Na2/3 [ Ni1/ $3 \mathrm{Mn} 2 / 3$ ] O 2. J. Electrochem. Soc. 148, 11. doi:10.1149/1.1407247.A1225

Luo, J., Sun, S., Peng, J., Liu, B., Huang, Y., Wang, K., et al. (2017). Graphene-rollwrapped prussian blue nanospheres as a high-performance binder-free cathode for sodium-ion batteries. ACS Appl. Mater. Interfaces 9 (30), 25317-25322. doi:10.1021/acsami.7b06334

Lv, W., Wang, Z., Cao, H., Sun, Y., Zhang, Y., and Sun, Z. (2018). A critical review and analysis on the recycling of spent lithium-ion batteries. ACS Sustain. Chem. Eng. 6 (2), 1504-1521. doi:10.1021/acssuschemeng.7b03811

Ma, X., Xiong, X., Zou, P., Liu, W., Wang, F., Liang, X., et al. (2019). "General and scalable fabrication of core-shell metal sulfides@C anchored on 3D N-doped foam toward flexible sodium ion batteries. Small 15-45. doi:10.1002/smll. 201903259

MacLaughlin, C. M. (2019). Status and outlook for magnesium battery technologies: a conversation with stan whittingham and sarbajit banerjee. ACS Energy Lett. 4 (2), 572-575. doi:10.1021/acsenergylett.9b00214

Maitra, U., House, R. A., Somerville, J. W., Tapia-Ruiz, N., Lozano, J. G., Guerrini, N., et al. (2018). Oxygen redox chemistry without excess alkalimetal ions in Na2/3Mg0.28Mn0.72O2. Nat. Chem. 10 (3), 288-295. doi:10. $1038 /$ nchem. 2923

Mao, M., Luo, C., Pollard, T. P., Hou, S., Gao, T., Fan, X., Cui, C., et al. (2019). A pyrazine-based polymer for fast-charge batteries. Angew. Chem. 58 (49), 17820-17826. doi:10.1002/anie.201910916

Ming, J., Guo, J., Xia, C., Wang, W., and Alshareef, H. N. (2019). Zinc-ion batteries: materials, mechanisms, and applications. Mater. Sci. Eng. R. Rep. 135, 58-84. doi:10.1016/j.mser.2018.10.002

Mossali, E., Picone, N., Gentilini, L., Rodrìguez, O., Pérez, J. M., and Colledani, M. (2020). Lithium-ion batteries towards circular economy: a literature review of opportunities and issues of recycling treatments. J. Environ. Manag. 264, 110500. doi:10.1016/j.jenvman.2020.110500

Nassar, N. T., Graedel, T. E., and Harper, E. M. (2015). By-product metals are technologically essential but have problematic supply. Sci. Adv. 1 (3), e1400180. doi:10.1126/sciadv. 1400180

Nayak, P. K., Yang, L., Brehm, W., and Adelhelm, P. (2018). From lithium-ion to sodium-ion batteries: advantages, challenges, and surprises. Angew. Chem. 57 (1), 102-120. doi:10.1002/anie.201703772

Ortiz-Vitoriano, N., Drewett, N. E., Gonzalo, E., and Rojo, T. (2017). High performance manganese-based layered oxide cathodes: overcoming the challenges of sodium ion batteries. Energy Environ. Sci. 10 (5), 1051-1074. doi:10.1039/C7EE00566K

Oshima, T., Kajita, M., and Okuno, A. (2004). "Development of sodium-sulfur batteries. Int. J. Appl. Ceram. Technol. 1 (3), 269-276. doi:10.1111/j.1744-7402. 2004.tb00179.x

Peng, F., Yu, L., Yuan, S., Liao, X. Z., Wen, J., Tan, G., et al. (2019). Enhanced electrochemical performance of sodium manganese ferrocyanide by $\mathrm{Na} 3$ (VOPO4)2F coating for sodium-ion batteries. ACS Appl. Mater. Interfaces 11 (41), 37685-37692. doi:10.1021/acsami.9b12041

Peters, J. F., Baumann, M., Zimmermann, B., Braun, J., and Weil, M. (2017). The environmental impact of Li-Ion batteries and the role of key parameters - a review. Renew. Sustain. Energy Rev. 67, 491-506. doi:10.1016/j.rser.2016.08.039

Ponrouch, A., Monti, D., Boschin, A., Steen, B., Johansson, P., and Palacín, M. R (2015). Non-aqueous electrolytes for sodium-ion batteries. J. Mater. Chem. 3 (1), 22-42. doi:10.1039/C4TA04428B

Qi, X., Liu, L., Song, N., Gao, F., Yang, G., Lu, Y., et al. (2017). Design and comparative study of $\mathrm{O} 3 / \mathrm{P} 2$ hybrid structures for room temperature sodiumion batteries. ACS Appl. Mater. Interfaces 9 (46), 40215-40223. doi:10.1021/ acsami.7b11282

Roskill (2019). Lithium: outlook to 2028. 16th Edn. Roskill. 
Shin, S. M., Kim, N. H., Sohn, J. S., Yang, D. H., and Kim, Y. H. (2005). Development of a metal recovery process from Li-ion battery wastes. Hydrometallurgy 79 (3-4), 172-181. doi:10.1016/j.hydromet.2005.06.004

Song, W., Jia, X., Wu, Z., Yanga, Y., Zhoua, Z., Lia, F., et al. (2014). Exploration of ion migration mechanism and diffusion capability for Na3V2(PO4)2F3 cathode utilized in rechargeable sodium-ion batteries. J. Power Sources 256, 258-263. doi:10.1016/j.jpowsour.2014.01.025

Solvay. Available at: https://www.solvay.com/en/brands/soda-solvay.

Sun, X., Hao, H., Hartmann, P., Liu, Z., and Zhao, F. (2019). Supply risks of lithium-ion battery materials: an entire supply chain estimation. Material. Today Energy 14, 100347. doi:10.1016/j.mtener.2019.100347

Swain, B. (2017). Recovery and recycling of lithium: a review. Separ. Purif. Technol. 172, 388-403. doi:10.1016/j.seppur.2016.08.031

U. G. Survey (2015). “Mineral commodity summaries 2015,” Mineral commodity summaries. Reston, VA: U.S. Geological Survey. doi:10.3133/70140094

USGS National Minerals Information Center (2020). Mineral commodity summaries 2020. . Reston, VA: U.S. Geological Survey.

Vaalma, C., Buchholz, D., Weil, M., and Passerini, S. (2018). A cost and resource analysis of sodium-ion batteries. Nat Rev Mater 3 (4), 1-11. doi:10.1038/ natrevmats. 2018.13

Velázquez-Martínez, V., Santasalo-Aarnio, R., and Serna-Guerrero, R. (2019). A critical review of lithium-ion battery recycling processes from a circular economy perspective. Batteries 5 (4), 68. doi:10.3390/batteries5040068

Vignarooban, K., Kushagra, R., Elango, A., Badami, P., Mellander, B. E., Xu, X., et al. (2016). Current trends and future challenges of electrolytes for sodium-ion batteries. Int. J. Hydrogen Energy 41 (4), 2829-2846. doi:10.1016/j.ijhydene.2015.12.090

Wang, B., Han, Y., Wang, X., Bahlawane, N., Pan, H., Yan, M., et al. (2018). Prussian blue analogs for rechargeable batteries. iScience 3, 110-133. doi:10. 1016/j.isci.2018.04.008

Wentker, M., Greenwood, M., Chofor Asaba, M., and Lekera, J. (2019). A raw material criticality and environmental impact assessment of state-of-the-art and post-lithium-ion cathode technologies. J. Energy Storage 26, 101022. doi:10. 1016/j.est.2019.101022

Xu, J., Lee, D. H., Clément, R. J., Yu, X., Leskes, M., Pell, A. J., et al. (2014). Identifying the critical role of Li substitution in P2-Na x [Li y Ni z Mn 1- y - z ] O $2(0<\mathrm{x} \mathrm{y} \mathrm{z}<1)$ intercalation cathode materials for high-energy Na-ion batteries. Chem. Mater. 26 (2), 1260-1269. doi:10.1021/cm403855t

Yabuuchi, N., Hara, R., Kubota, K., Paulsen, J., Kumakura, S., and Komaba, S. (2014). A new electrode material for rechargeable sodium batteries: P2-type Na 2/3 [Mg 0.28 Mn 0.72 ]O 2 with anomalously high reversible capacity. J. Mater. Chem. 2 (40), 16851-16855. doi:10.1039/C4TA04351K

Yabuuchi, N., Kubota, K., Dahbi, M., and Komaba, S. (2014). Research development on sodium-ion batteries. Chem. Rev. 114 (23), 11636-11682. doi: $10.1021 / \mathrm{cr} 500192 \mathrm{f}$
Yao, Y., Zhu, M., Zhao, Z., Tong, B., Fan, Y., and Hua, Z. (2018). Hydrometallurgical processes for recycling spent lithium-ion batteries: a critical review. ACS Sustain. Chem. Eng. 6 (11), 13611-13627. doi:10.1021/acssuschemeng.8b03545

You, Y., and Manthiram, A. (2018). Progress in high-voltage cathode materials for rechargeable sodium-ion batteries. Adv. Energy Material. 8. 2. doi:10.1002/ aenm.201701785

You, Y., Wu, X.-L., Yin, Y.-X., and Guo, Y.-G. (2014). High-quality Prussian blue crystals as superior cathode materials for room-temperature sodiumion batteries. Energy Environ. Sci. 7 (5), 1643-1647. doi:10.1039/ C3EE44004D

Yu, M., Yin, Z., Yan, G., Wang, Z., Guo, H., Li, G., et al. (2020). Synergy of interlayer expansion and capacitive contribution promoting sodium ion storage in S, N-Doped mesoporous carbon nanofiber. J. Power Sources 449, 227514. doi:10.1016/j.jpowsour.2019.227514

Zhang, H. (2019). Polyanionic cathode materials for sodium-ion batteries. Karlsruhe: Karlsruhe Institute of Technology.

Zhao, N., Li, C., and Guo, X. (2014). Long-life Na-O 2 batteries with high energy efficiency enabled by electrochemically splitting $\mathrm{NaO} 2$ at a low overpotential. Phys. Chem. Chem. Phys. 16 (29), 15646-15652. doi:10.1039/ C4CP01961J

Zhao, Q., Lu, Y., and Chen, J. (2017). Advanced organic electrode materials for rechargeable sodium-ion batteries. Adv. Energy Mater. 7 (8), 1601792. doi:10. 1002/aenm.201601792

Zheng, L., Li, J., and Obrovac, M. N. (2017). "Crystal structures and electrochemical performance of air-stable $\mathrm{Na} 2 / 3 \mathrm{Ni} 1 / 3-\mathrm{x} \mathrm{Cu}$ x Mn 2/3 O 2 in sodium cells. Chem. Mater. 29 (4), 1623-1631. doi:10.1021/acs.chemmater.6b04769

Zheng, X., Zhu, Z., Lin, X., Zhang, Y., He, Y., Cao, H., et al. (2018). A mini-review on metal recycling from spent lithium ion batteries. Engineering 4 (3), 361-370. doi:10.1016/j.eng.2018.05.018

Zhu, X., Lin, T., Manning, E., Zhang, Y., Yu, M., Zuo, B., et al. (2018). Recent advances on Fe- and Mn-based cathode materials for lithium and sodium ion batteries. J. Nano Res. 20 (6). doi:10.1007/s11051-018-4235-1

Conflict of Interest: The authors declare that the research was conducted in the absence of any commercial or financial relationships that could be construed as a potential conflict of interest.

Copyright (c) 2020 Karabelli, Singh, Kiemel, Koller, Konarov, Stubhan, Miehe, Weeber, Bakenov and Birke. This is an open-access article distributed under the terms of the Creative Commons Attribution License (CC BY). The use, distribution or reproduction in other forums is permitted, provided the original author(s) and the copyright owner(s) are credited and that the original publication in this journal is cited, in accordance with accepted academic practice. No use, distribution or reproduction is permitted which does not comply with these terms. 